\title{
Planeamiento estratégico local y evaluación del desarrollo urbano sostenible integrado en ciudades medias
}

\section{Local strategic planning and integrated sustainable urban development assessment in medium-sized cities}

\author{
Blanca del Espino Hidalgo \\ Universidad de Sevilla \\ blancadel86@gmail.com
}

\begin{abstract}
NOTA BIOGRÁFICA
Departamento de Historia, Teoría y Composición Arquitectónicas. Acreditada Profesor Ayudante Doctor. Doctora en Arquitectura, Máster en Ciudad y Arquitectura Sostenibles, Máster en Arquitectura y Patrimonio Histórico y Arquitecta por la Universidad de Sevilla. Actualmente, disfruta un Contrato Postdoctoral de Perfeccionamiento en el Extranjero de Plan Propio de Investigación de la Universidad de Sevilla en Dipartimento di Architettura e Studi Urbani del Politenico di Milano (Italia). Es miembro del grupo PAIDI Patrimonio y Desarrollo Urbano Patrimonial en Andalucía (HUM 700). Sus investigaciones abordan, desde una perspectiva interdisciplinar, la sostenibilidad del patrimonio urbano, incluyendo el desarrollo de indicadores, cartografía, paisaje, turismo y participación ciudadana.
\end{abstract}

\author{
Daniel Navas Carrillo \\ Universidad de Sevilla \\ dnavas@us.es
}

\section{NOTA BIOGRÁFICA}

Departamento de Urbanística y Ordenación del Territorio. Contratado Predoctoral, Arquitecto por la Universidad de Málaga, Máster en Innovación en Arquitectura y Máster en Arquitectura y Patrimonio Histórico por la Universidad de Sevilla. Miembro del grupo PAIDI Patrimonio y Desarrollo Urbano Patrimonial en Andalucía (HUM 700) y del Instituto Universitario de Arquitectura y Ciencias de la Construcción. Su línea principal de investigación se centra en el reconocimiento, protección y conservación de barriadas residenciales construidas en la segunda mitad del siglo xx en ciudades de escala intermedia.

\section{RESUMEN}

Las políticas de Desarrollo Urbano Sostenible Integrado actuales exigen una monitorización continuada y reiterativa de las iniciativas previstas o puestas en práctica. A este respecto, un consorcio de organismos europeos ha desarrollado y puesto a disposición de los planificadores una herramienta diseñada de manera específica para evaluar la visión integrada de planes, proyectos y acciones ideadas y/o desarrolladas en pequeñas, medianas o grandes ciudades de toda Europa: el Reference Framework for Sustainable Cities (RFSC). Este trabajo presenta los resultados del análisis comparado de dos planes estratégicos diseñados para Lucena, una ciudad media en el sur de Córdoba, España, desde la evaluación de su visión integrada. Las ciudades medias han sido consideradas desde las directrices europeas como la categoría urbana con mejores cualidades para la sostenibilidad urbano-territorial. 
GAPP. Nueva Época - N. ${ }^{\circ}$ 20, noviembre 2018 - ISSN: 1989-8991 - DOI: 10.24965/gapp.v0i20.10481 - [Págs. 143-163] Número monográfico - Gobernanza y políticas de desarrollo urbano: teoría y práctica

Planeamiento estratégico local y evaluación del desarrollo urbano sostenible integrado en ciudades medias Blanca del Espino Hidalgo / Daniel Navas Carrillo

\title{
PALABRAS CLAVE
}

Planeamiento estratégico; RFSC; visión integrada; DUSI; ciudades medias; sostenibilidad urbana; indicadores.

\begin{abstract}
Current Integrated Sustainable Urban Development politics require a continuous and reiterative monitorization of the in-progress actions or proposed initiatives. Thus, a European countries-based consortium created and made available to the planners a tool specifically designed to evaluate the integrated vision of plans, projects and interventions devised and/or developed within small, medium or big cities all over Europe: The Reference Framework for Sustainable Cities (RFSC). This work aims to present the outcomes of the compared analysis between two strategic plans developed in Lucena, a medium-sized city in the South of Cordoba (Spain), focusing on their integrated vision. Medium-cities have been considered by the European guidelines as the urban category with the best qualities for urban-territorial sustainability.
\end{abstract}

\section{KEYWORDS}

Strategic planning; RFSC; integrated vision; ISUD; medium-sized cities; urban sustainability; indicators.

\section{SUMARIO}

1. INTRODUCCIÓN. 1.1. DEFINICIÓN DE CIUDAD MEDIA Y DEBATE SOBRE SU SOSTENIBILIDAD. 1.2. EVOLUCIÓN EN LOS MODELOS DE PLANIFICACIÓN Y REGENERACIÓN URBANA. 1.3. LUCENA Y SU PLANIFICACIÓN ESTRATÉGICA COMO CASO DE ESTUDIO. 2. METODOLOGÍA. 2.1. LA HERRAMIENTA RFSC PARA LA EVALUACIÓN DEL MODELO DUSI: ORIGEN, DESARROLLO Y ACTUALIDAD. 2.2. CRITERIOS PARA LA APLICACIÓN DE LA HERRAMIENTA AL CASO DE ESTUDIO ESCOGIDO (LUCENA, CÓRDOBA). 3. RESULTADOS. 3.1. APLICACIÓN DE LA HERRAMIENTA RFSC AL PRIMER PLAN ESTRATÉGICO DE LUCENA. 3.2. APLICACIÓN DE LA HERRAMIENTA RFSC AL SEGUNDO PLAN ESTRATÉGICO DE LUCENA. 4. DISCUSIÓN.

\section{INTRODUCCIÓN}

El concepto de Desarrollo Sostenible, acuñado en el informe Our common future (Brundtland et al., 1987) y desarrollado en la Declaración de Río de 1992, ha evolucionado a lo largo de las últimas décadas tanto en su definición como en los ámbitos a los que se aplica, las dimensiones o áreas que contempla y la manera en la que debe ser aplicado a la práctica urbana. En 2013, treinta años después de la Comisión Mundial de Medio Ambiente y Desarrollo de las Naciones Unidas que daría pie a la redacción de dicho informe, el Consejo de la Unión Europea aprobó su política de cohesión para el período 2014-2020, en la que se acuñaba el modelo de Desarrollo Urbano Sostenible Integrado «con el fin de reforzar la resiliencia de las ciudades y garantizar las sinergias entre las inversiones financiadas por los Fondos Estructurales y de Inversión Europeos» (Consejo de la Unión Europea, 2014: 2).

Así pues, se trata de una serie de directrices para formular políticas urbanas, estrechamente ligadas a la financiación de actuaciones y a la articulación de estas. En este sentido, la aplicación de estrategias integradas dentro de este marco oficial exige, de manera inapelable, una monitorización continuada y reiterativa de las iniciativas previstas o puestas en práctica. En muchos casos, el diseño, la visualización y ponderación de los resultados e impactos de las mismas supone una de las principales dificultades habida cuenta de la complejidad de cuantificar aspectos que son, por definición propia, cualitativos (Galindo, 2010).

En este sentido, han sido numerosos y continuados los esfuerzos que tanto desde la academia como desde los organismos oficiales se han realizado en aras de conseguir evaluar tanto la sostenibilidad de las acciones encaminadas a mejorar el estado y mantenimiento de las ciudades como, posteriormente, a monitorizar el éxito de la aplicación de las políticas públicas y a testar su progreso y adecuada implementación (Subirats, 1994: 149).

Este trabajo tiene como objetivo fundamental la puesta en carga de una de las últimas herramientas que instituciones europeas han previsto para la evaluación de la integración y sostenible de proyectos urbanos y territoriales de distinta índole: el Marco de Referencia para Ciudades Sostenibles. Para llevarlo a cabo, 
GAPP. Nueva Época - N. 20, noviembre 2018 - ISSN: 1989-8991 - DOI: 10.24965/gapp.v0i20.10481 - [Págs. 143-163] Número monográfico - Gobernanza y políticas de desarrollo urbano: teoría y práctica

Planeamiento estratégico local y evaluación del desarrollo urbano sostenible integrado en ciudades medias Blanca del Espino Hidalgo / Daniel Navas Carrillo

se realizará la evaluación, como caso de estudio, de dos instrumentos de planificación urbana local para la misma ciudad: Lucena, una ciudad media en el sur de Córdoba, que ha realizado dos Planes Estratégicos que contaban con la sostenibilidad y el diseño integrado entre sus principios.

De este modo se pondrá en cuestión, por una parte, la evolución en los modos de planificación a lo largo de las últimas décadas y, por otra, la eficacia de la aplicación de la mencionada herramienta.

\subsection{Definición de ciudad media y debate sobre su sostenibilidad}

Las ciudades medias han sido consideradas desde las directrices europeas como la categoría urbana con mejores cualidades para la sostenibilidad urbano-territorial (Unión Europea, 2011: VII), lo que ha fomentado el incremento de su protagonismo de las estrategias de ordenación y desarrollo territorial, así como en las políticas marco.

En la segunda mitad del siglo Xx muchos países de la Unión Europea enfocaron parte de sus políticas de desarrollo en la dinamización de las ciudades medias, como medida para frenar los procesos de despoblamiento del ámbito rural causantes de los graves problemas de hacinamiento de las grandes ciudades (Navas Carrillo, 2016: 14). Estos primeros intentos derivan de la teoría de los lugares centrales de Walter Christaller (1933), ampliada por Auguste Lösch (1940) en su obra La Organización Espacial de la Economía y del contradictorio concepto de polo de desarrollo en el ámbito regional utilizado por Perroux (1955). Sería Hirschman (1958) el encargado de formular un cuerpo teórico suficiente para su utilización en la planificación territorial, ya en los años 60 , como una de las medidas para la promoción de las posteriormente denominadas ciudades intermedias.

Es evidente que el interés actual difiere del comentado, situando en el marco de la sostenibilidad -en todas sus dimensiones- la defensa de un modelo territorial policéntrico, en el que cada uno de sus centros son «susceptibles de generar crecimiento y desarrollo en su entorno próximo y de equilibrar el territorio frente a las macrocefalias metropolitanas» (Vilagrasa, 2000). En este sentido, en los últimos años, esta categoría urbana está suscitando especial interés por la calidad de vida que presenta al carecer de muchos de los problemas medioambientales de las grandes ciudades, así como por la propia escala de la ciudad que la hace más humana y accesible. Por otra parte, las ciudades medias propician un uso más racional de los recursos, garantizando el acceso a bienes y servicios especializados en condiciones similares a las que se realizan en las grandes áreas urbanas (Llop Torné y Hoeflich de Duque, 2007: 10).

En cuanto a su definición, lo primero que cabe clarificar es que esta no debe realizarse exclusivamente en términos demográficos, sino que deben entenderse por su posición estratégica dentro de la organización funcional de una comarca o ámbito regional próximo, y alejadas de las sinergias de los principales centros regionales, tal como se recoge en el Informe de la Unesco sobre ciudades intermedias de 1999 (Bellet Sanfeliu y Llop Torné).

Este informe señala como principal problema de definición la cuestión demográfica. Si en el ámbito europeo la población media de una ciudad intermedia se sitúa entre 20.000-500.000 habitantes, en América se consideran poblaciones entre los 200.000 y 500.000 , llegando en el caso de Argentina a ampliarse el rango entre los 50.000 y el millón de habitantes. Discrepancias evidentes si se tiene en cuenta que según Plotnicov (1994: 285) el tamaño de estas ciudades no debe medirse en términos absolutos, sino que debería utilizarse la expresión rango-tamaño. Con ella se hace referencia a los rangos poblacionales que caracterizan a la ocupación territorial del conjunto de ciudades y que permitirán definir -en términos demográficos- lo que se entiende por ciudad media en cada territorio.

Esto no quiere decir que en cualquier contexto pueda identificarse una red de ciudades medias, como por ejemplo ocurre en Gran Bretaña, Canadá o Australia. Tampoco quiere decir que siempre se mantenga una distribución armónica entre las distintas escalas urbanas, como puede ser el caso de México, en el que las ciudades principales doblan en número a las intermedias, más próximas a las de ámbito rural. Entonces, ¿cómo puede reconocerse el papel que juegan las ciudades medias en su territorio?

Según este informe, el concepto de ciudad media debe ir más allá de la simple posición intermedia entre el extremo superior, las grandes áreas metropolitanas, y el inferior, el ámbito rural. Se requiere contextualizar en base a las condiciones socioeconómicas y culturales particulares de cada territorio, y que determinarán el papel de cada municipio, con independencia del número de habitantes que tenga. Para Bellet Sanfeliu y Beltrão Sposito, (2009: 43), «las ciudades medias articulan el territorio y funcionan como centros de referencia para un territorio más o menos inmediato. Y es precisamente ese papel y esa relación, que los centros mantienen con su territorio, lo que ayuda a definir con más claridad el mismo concepto». 
GAPP. Nueva Época - N. ${ }^{\circ}$ 20, noviembre 2018 - ISSN: 1989-8991 - DOI: 10.24965/gapp.v0i20.10481 - [Págs. 143-163] Número monográfico - Gobernanza y políticas de desarrollo urbano: teoría y práctica

Planeamiento estratégico local y evaluación del desarrollo urbano sostenible integrado en ciudades medias

De acuerdo con estos autores, las principales características que las definen serían: ser centro servidor de bienes y servicios para el propio municipio y los más cercanos; ser centro de interacción social, económica y funcional; tener una estrecha relación con redes de infraestructuras locales, regionales, nacionales o internacionales; o contar con la localización de organismos de administración regional con servicio a otros municipios cercanos.

Con el objeto de descender al caso de estudio concreto sobre el que se efectúa este trabajo, se comprueba que este reconocimiento subyace en la redacción del Plan de Ordenación del Territorio de Andalucía (aprobado por el Decreto 206/2006, de 28 de noviembre), el cual propone una estructura territorial de tipo jerárquico que denomina Sistema de Ciudades distinguiendo tres categorías de ciudades: Centros Regionales, Ciudades Medias y Áreas Rurales. Para el sistema de ciudades medias, identifica a su vez dos escalas o niveles internos, quedando aproximadamente el $60 \%$ del territorio autonómico bajo la influencia de una ciudad media (Del Espino Hidalgo, 2015: 103), representando en términos poblacionales cerca de un 15\% de los habitantes que residen en toda la comunidad (Navas-Carrillo et al., 2016: 8).

Esta clasificación en dos niveles ha sido realizada en base al tamaño demográfico, diversidad y dinámica de su base económica y peso funcional, sin haberse identificado una clara definición para cada uno de los niveles de ciudad media en todo el plan. Se ha comprobado que -salvo ciertas excepciones- en términos demográficos, las ciudades medias de primer nivel se corresponden con poblaciones entre 100.000 y 30.000 habitantes, mientras que las de segundo nivel con poblaciones menores entre 30.000 y 15.000 habitantes, coincidiendo con la hipótesis de Merinero Rodríguez y Lara de Vicente (2010: 2). Sin embargo, tal como señalan autores como Cano García (2008: 17) esta distinción responde más a una posición de centralidad dentro de sus unidades territoriales que realmente a una cuestión de tamaño o especialización funcional, a pesar de que en la mayoría de casos ambas circunstancias sean coincidentes.

El plan andaluz va incluso más allá, y defiende que las dimensiones y características de las ciudades medias posibilitan un modelo urbano compacto, en el que el crecimiento sea controlado con el fin de limitar el consumo excesivo de suelo, y en el que se garantice la conservación de los valores y características propias de estas ciudades, al tiempo de que se busque aumentar la calidad de vida de sus habitantes completando lo ya existente con infraestructuras y dotaciones que favorezcan el desarrollo económico de la comarca (Navas Carrillo, 2016: 8-9).

Por tanto, las ciudades medias se presentan como piezas clave en la consecución de un modelo territorial más sostenible, al contribuir funcionalmente a la vertebración y cohesión del territorio de cualquier región y, concretamente, la Comunidad Autónoma andaluza. Es por ello por lo que las políticas de planificación desarrolladas en esta escala urbana se vislumbran como potenciales elementos para ser evaluadas a partir de los criterios del Desarrollo Urbano Sostenible Integrado a través de la aplicación de la herramienta RFSC.

\subsection{Evolución en los modelos de planificación y regeneración urbana}

La planificación estratégica local se identifica como una herramienta fundamental para alcanzar objetivos de sostenibilidad a escala urbana, reconocida a nivel internacional como una renovación con respecto al planeamiento tradicional, inicialmente asociada al fomento del desarrollo socioeconómico a escala local (Martín y Merinero, 2010: 15). La principal innovación introducida con respecto a los modelos anteriores es la inclusión de la gobernanza para el diseño, la elaboración y la implementación de las políticas públicas.

En este sentido, en la planificación estratégica urbana aparecen cuestiones como la participación ciudadana, la colaboración público-privada o la cooperación territorial (Barton, 2006: 27-45), lo que introduce, además, las dimensiones económica y social dentro de los pilares clásicos de la sostenibilidad (Elkington, 1994: 90-100). En cualquier caso, la introducción de estas cuestiones supone dos cambios sustantivos: por una parte, la incorporación de diferentes áreas técnicas, profesionales y de conocimiento -incluyendo la sociología, la politología, la economía o la ecología, entre otras- en los procesos de planificación; por otra parte, la superación de la cualidad espacial o incluso geométrica como la principal cuestión a tener en cuenta en el diseño de la ciudad, lo que supone una revitalización del concepto de territorio, de ciudad y de las variables que los dinamizan.

Este hecho ha provocado, en gran medida, un nuevo énfasis en las políticas de regeneración y rehabilitación urbana, así como la búsqueda de fuentes específicas para su financiación, una buena parte de las cuales proceden de políticas de intervención en la ciudad que tienen su origen en las directrices europeas (Huete García, et. al., 2014: 51), generalmente sensibilizadas con estas cuestiones. Cobran especial importancia en este contexto los Fondos Europeos de Desarrollo Regional (FEDER), que a lo largo de dos 
GAPP. Nueva Época - N. 20, noviembre 2018 - ISSN: 1989-8991 - DOI: 10.24965/gapp.v0i20.10481 - [Págs. 143-163] Número monográfico - Gobernanza y políticas de desarrollo urbano: teoría y práctica

Planeamiento estratégico local y evaluación del desarrollo urbano sostenible integrado en ciudades medias Blanca del Espino Hidalgo / Daniel Navas Carrillo

décadas han proporcionado recursos económicos a regiones europeas especialmente débiles entre las que ha destacado Andalucía -por constituir una región con gran presencia del sector primario en su estructura productiva- $y$, más concretamente, los centros históricos de sus ciudades -por considerarse fragmentos urbanos con un especial porcentaje de habitantes en riesgo de exclusión social- y, posteriormente, las barriadas periféricas -por similares razones-.

Mediante las iniciativas URBAN (1994-1999), URBAN II (2000-2006) y URBANA (2007-2013) se acometieron proyectos de mejora de áreas urbanas y barrios en situación de crisis, de cara a su desarrollo sostenible (ver Huete, García, et. al. 2014), logrando la actuación en 118 zonas urbanas en su primera fase, 70 en la segunda (Comisión Europea, 2000) y 46 en la tercera (RIU, 2013).

En la actualidad, los fondos europeos han sido reemplazados por una convocatoria de Fondos Estructurales vinculadas a acciones DUSI (de Desarrollo Urbano Sostenible Integrado), cuya primera convocatoria para España tuvo lugar a finales del año 2015 y que, en el momento de redacción de este artículo, aún no ha sido resuelta. Esta iniciativa tiene una perspectiva de acción para para el período 2014-2020, y presenta, como novedad, la obligatoriedad de que las ciudades que concurran a la convocatoria tengan definida una estrategia urbana sostenible integrada, dentro de la cual se incluyan las acciones para las cuáles se solicita ayuda económica (Orden HAP, 2015).

Es por esto que, en la actualidad, la planificación integrada de ciudades se entiende no limitada a zonas específicas, sino que dicha intervención ha de hacerse extensiva a la ciudad en su conjunto y a retos no necesariamente vinculados a actuaciones materiales de construcción o urbanización (RIU, 2015: 6-7).

Por tanto, se considera el Desarrollo Urbano Sostenible Integrado como el paradigma de la sostenibilidad urbana a ser considerado de cara a este estudio, y la planificación estratégica como la estrategia de intervención que mejor se adapta al mismo, y que será objeto de evaluación más adelante en este trabajo.

\subsection{Lucena y su planificación estratégica como caso de estudio}

Tal como se ha mencionado, el Plan de Ordenación del Territorio de Andalucía distingue dos niveles de ciudades medias en su establecimiento del sistema urbano regional. Las ciudades que pertenecen al nivel 1 son especialmente relevantes tanto en su demografía como en su dinamismo territorial y urbano, y entre este grupo se encuentra, en el centro de Andalucía, la ciudad de Lucena, segunda en población de la provincia de Córdoba tras la capital.

Lucena es, por tanto, una de las tres principales ciudades medias del interior andaluz -junto a Écija y Antequera- y, según el padrón publicado en 2016, la más poblada de las tres con 42,615 habitantes ${ }^{1}$. Considerada como una de las grandes agrociudades durante décadas (López Ontiveros, 1994: 66) y con un pasado estrechamente vinculado a la agricultura, experimentó un fuerte cambio a finales del siglo XX con la incorporación de un sistema productivo local basado en la industria de la madera y, más adelante, del frío industrial (Caravaca et al., 2002: 164), que provocó un alto crecimiento en el empleo y, por tanto, en el número de habitantes. Esto ha sido acompañado por la creación de nuevas barriadas periféricas con diferentes criterios en cuanto a su diseño y articulación fruto, entre otras cuestiones, de instrumentos de planificación insuficientes y de llegada tardía (Campos y Abarca, 2013: 301).

Además del sector industrial, Lucena destaca en la actualidad por ser un importante centro comarcal a nivel servicios, lo que refuerza su posición como centro secundario (Feria Toribio, 1984: 134) en el sur de la provincia y, en general, en el interior de Andalucía. Este hecho está favorecido, en parte, por su posición central en la región y por estar enclavada cerca de rutas principales de comunicación mediante carretera: la A-45 que une Córdoba con Málaga y la futura A-318, conocida como Autovía del Aceite, cuya construcción se encuentra en marcha -actualmente uno de sus tramos funciona como desvío del centro urbano de Lucena- y que unirá, en un futuro, la A-92 a la altura de Estepa con A-316 en Jaén, convirtiéndose en un eje longitudinal andaluz de primer orden (Del Espino Hidalgo, 2017: 186).

El dinamismo social y económico han condicionado, por otra parte, su sostenibilidad a nivel urbano, lo que la convierte en uno de los casos de estudio más peculiares de entre las ciudades medias andaluzas (Del Espino Hidalgo, 2017: 184). A pesar de que este hecho no ha tenido grandes implicaciones sobre su planificación urbanística, sí que ha propiciado, como se comenta previamente, la aparición de dos instrumentos de

1 Fuente: Sistema Multiterritorial de Información de Andalucía (www.sima.es). Al cierre de redacción de este artículo, los datos definitivos del Censo 2017 no han sido aún publicados. 
GAPP. Nueva Época - N. 20, noviembre 2018 - ISSN: 1989-8991 - DOI: 10.24965/gapp.v0i20.10481 - [Págs. 143-163] Número monográfico - Gobernanza y políticas de desarrollo urbano: teoría y práctica

Planeamiento estratégico local y evaluación del desarrollo urbano sostenible integrado en ciudades medias

planificación estratégica que recogen la necesidad de innovación en las maneras de gestionar una ciudad cuya expansión y centralismo territorial han generado en sí mismos nuevos retos a tener en cuenta.

Así pues, la ciudad redacta su primer Plan Estratégico en el año 2002 (Ayuntamiento de Lucena, 2002) y obtiene, en dos convocatorias consecutivas, Fondos Europeos de Desarrollo Regional (FEDER) que contribuyen a un alto grado de ejecución del mismo y que se tradujeron, por lo general, en una renovación de su centro histórico a nivel tanto de espacio público como de espacios edificados de especial interés patrimonial que se han convertido, en su mayoría, en dependencias municipales relacionadas con usos culturales.

Posteriormente, en el año 2015, se lanza el Segundo Plan Estratégico de Lucena (Ayuntamiento de Lucena, 2015) que supera la noción de sostenibilidad para incorporar el concepto de Desarrollo Urbano Sostenible Integrado entre sus principios. Este plan ha sido una baza fundamental para obtener, en la segunda convocatoria de Estrategias de Desarrollo Urbano Sostenible Integrado (EDUSI) de Fondos Comunitarios del presupuesto de la UE, gestionados y adjudicados por el Ministerio de Hacienda y Función Pública (Ministerio de Hacienda, 2016), la financiación necesaria para el desarrollo de una parte de su estrategia urbana.

Por tanto, la experiencia de Lucena en el manejo de cuestiones relativas a sostenibilidad e integración urbana dentro de proyectos de planificación, unida a su posición estratégica tanto a nivel territorial como funcional, la convierten en un buen ejemplo de ciudad media europea sobre la que aplicar la herramienta internacional de medición de la sostenibilidad urbana que se describe a continuación.

\section{METODOLOGÍA}

\subsection{La herramienta RFSC para la evaluación del modelo DUSI: origen, desarrollo y actualidad}

Como decíamos, la evolución de las políticas de intervención en la ciudad introducidas en las agendas de desarrollo a distintas escalas -desde la urbana a la internacional- pone de manifiesto la necesidad de un cambio de paradigma en el que entra en juego, como factor clave, la integralidad (De Gregorio Hurtado, 2010: 45-46). En este sentido, las dimensiones económica, cultural, social, medioambiental o territorial se enfocan de manera conjunta para establecer diagnósticos, mientras que las soluciones adoptadas deben responder a una perspectiva integral (Huete García et. al., 2017: 322). Este proceso da como consecuencia, de manera más reciente, la introducción del concepto de Desarrollo Urbano Sostenible Integrado como paradigma para el entendimiento actual de la sostenibilidad en ciudades.

Por tanto, a la hora de seleccionar una herramienta para la evaluación de la planificación estratégica desde una perspectiva integrada basada en el modelo DUSI, será necesario que ésta cuente con la posibilidad de establecer un análisis de marcado carácter interdimensional y que, en la medida de lo posible, permita medir el equilibrio entre las dimensiones aceptadas por los principales instrumentos y directrices en materia de sostenibilidad.

En la ya mencionada Conferencia de Río de 1992 se sientan las bases del desarrollo sostenible, que se articulan posteriormente mediante la redacción de la Carta de las Ciudades Europeas hacia la Sostenibilidad Carta de Aalborg (Conferencia Europea, 1994). En este documento se explicita cuáles son las claves para el desarrollo sostenible de los asentamientos urbanos y se pone de manifiesto la importancia de las políticas de gestión, así como su articulación con la implicación de la propia ciudadanía, para el crecimiento integrado de las urbes (Del Espino, 2016: 223).

Los primeros intentos al respecto vinieron derivados de los dos eventos previamente mencionados: la declaración de 1992 establece la voluntad de crear una Agenda 21 Global para el trabajo conjunto en aras del desarrollo sostenible y, con la llegada de la Carta de Aalborg, la responsabilidad se traslada de manera fáctica a los municipios, creándose el concepto de Agenda 21 Local de Desarrollo Local Sostenible, conocida como Agenda 21 Local (Conferencia Europea, 1994: Art.28). La propia Agenda 21 Global, en su Capítulo 40 , mencionaba ya la necesidad de crear indicadores para la toma de decisiones que afectasen desarrollo sostenible en las ciudades:

«Es necesario desarrollar indicadores de desarrollo sostenible para proveer de bases sólidas a la toma de decisiones a todos los niveles y para contribuir a una sostenibilidad autorregulada de sistemas ambientales y de desarrollo integrados.» (Conferencia de las Naciones Unidas, 1992: Cap. 40).

La puesta en marcha de los principios de la Agenda21 Local en los municipios españoles tuvo desigual éxito dependiendo, en gran medida, de la presión ejercida por las diputaciones provinciales que se responsabilizaban de su correcta ejecución. Por otra parte, la ausencia de un sistema único para el diseño y la aplicación de indicadores de sostenibilidad para los municipios, unida a la disparidad de condiciones y escalas 
GAPP. Nueva Época - N. 20, noviembre 2018 - ISSN: 1989-8991 - DOI: 10.24965/gapp.v0i20.10481 - [Págs. 143-163] Número monográfico - Gobernanza y políticas de desarrollo urbano: teoría y práctica

Planeamiento estratégico local y evaluación del desarrollo urbano sostenible integrado en ciudades medias Blanca del Espino Hidalgo / Daniel Navas Carrillo

entre los mismos, propició la aparición de multitud de sistemas de evaluación y referencias, la mayoría de ellos diseñados para grandes ciudades (Del Espino Hidalgo, 2015: 489-505).

En 2008, un consorcio de organismos europeos liderados por el Council of European Municipalities and Regions (CEMR) y tres entidades francesas -Centre d'études et d'expertise sur les risques, l'environnement, la mobilité et l'aménagement (CEREMA), Ministère du Logement et de l'Habitat Durable y Fédération Nationale des Agences d'Urbanisme (FNAU)- comienza a desarrollar y poner a prueba una herramienta diseñada de manera específica para evaluar la visión integrada de planes, iniciativas y acciones ideadas y/o desarrolladas en pequeñas, medianas o grandes ciudades de toda Europa: el Marco de Referencia para Ciudades Sostenibles o, según su denominación en lengua inglesa, Reference Framework for Sustainable Cities (en adelante, RFSC).

La propuesta se llevó a cabo a raíz de la publicación de la Carta de Leipzig (Encuentro de Ministros, 2007), y pretendía aportar un carácter operativo a los acuerdos y principios alcanzados en aquella reunión y fijados en dicho documento. Su redacción respondía, además, a dos objetivos fundamentales: por una parte, unificar los criterios y el lenguaje utilizados en todos los municipios europeos al hablar de sostenibilidad urbana y, por otra parte, sintetizar los diferentes sistemas de indicadores existentes en cada uno de los países, regiones y ciudades ${ }^{2}$.

La herramienta tuvo una primera fase de aplicación y testeo hasta el final del año 2014, durante la cual se lanzó una versión beta junto con la que se elaboraron seminarios para su aprendizaje en todas las ciudades europeas que estuviesen interesadas en su aplicación. Estos encuentros, además, servían como fuentes para la recopilación de sugerencias, problemas, dificultades y propuestas de mejora de cara al lanzamiento de una segunda versión, revisada y mejorada, en el Congreso CEMR Congress celebrado en Nicosia, Chipre, en abril de 2016 (RFSC, 2016).

La herramienta, en su versión actual, puede utilizarse mediante un registro previo tanto para evaluación de proyectos urbanos reales - previa autorización de un responsable- como para testear la propia herramienta mediante un modelo o proyecto ficticio. La configuración disponible para la evaluación del RFSC permite:

- Establecer una red de contactos que permitan intercambiar experiencias entre diferentes ciudades y trabajar en equipo, así como conocer buenas prácticas de otros municipios.

- Aplicar prioridades de cualquier instrumento de planificación urbana, sea cual sea su escala y estado de diseño/aplicación, sobre un listado de cuestiones que permiten, además, evaluar el impacto de las diferentes acciones.

- Utilizar indicadores de evaluación provistos por la propia herramienta y seleccionados desde un amplio catálogo en el que se distingue entre indicadores recomendados y secundarios.

- Visualizar los resultados obtenidos tanto en el establecimiento de prioridades como en la evaluación de impacto, según diferentes marcos conceptuales y normativos.

Con respecto a este último punto, merece ser destacado el hecho de que la herramienta integre, además de la evaluación en base a las cinco dimensiones que en ella se distinguen -espacial, social, económica, medioambiental y de gobernanza-, la visualización de resultados en función de parámetros establecidos por otros documentos marco y por metodologías contrastadas de carácter internacional para la medición de la sostenibilidad:

- La Carta de Aalborg (Conferencia Europea, 1994).

- Los cuatro pilares clásicos de la sostenibilidad.

- La Norma ISO 37101 para la gestión sostenible de las comunidades (AENOR, 2016).

- Los principios de los ÉcoQuartiers (EcoBarrios) franceses (Ministère du Logement, 2017).

- Los diecisiete Objetivos de Desarrollo Sostenible de la Organización de las Naciones Unidas (ONU, 2015).

Más recientemente, se ha puesto a disposición del usuario una nueva herramienta de evaluación que, de manera directa, evalúa los diecisiete Objetivos de Desarrollo Sostenible en base a una serie formada por setenta indicadores específicos que se distribuyen entre los distintos objetivos, lo que incide en la idea de alinear los criterios de evaluación con las directrices provistas por los estamentos de carácter internacional acerca de la futura sostenibilidad del planeta y, más concretamente en este caso, de las ciudades.

2 Puede ampliarse esta información en la página web del Ministerio de Fomento de España, https://www.fomento.gob.es/MFOM/ LANG_CASTELLANO/DIRECCIONES_GENERALES/ARQ_VIVIENDA/SUELO_Y_POLITICAS/SOTENIBILIDAD/RFSC/ (Última consulta el 10/07/2017). 
GAPP. Nueva Época - N. 20, noviembre 2018 - ISSN: 1989-8991 - DOI: 10.24965/gapp.v0i20.10481 - [Págs. 143-163] Número monográfico - Gobernanza y políticas de desarrollo urbano: teoría y práctica

Planeamiento estratégico local y evaluación del desarrollo urbano sostenible integrado en ciudades medias Blanca del Espino Hidalgo / Daniel Navas Carrillo

Es debido a todo lo anterior que, de cara a la metodología de evaluación aplicada a este trabajo, se selecciona la herramienta RFSC como la idónea por los siguientes motivos:

- Parte de un enfoque multidimensional e integrado como base para su definición.

- Permite establecer comparaciones y obtener conclusiones sobre el equilibrio entre las distintas dimensiones abordadas, lo que potencia la visión integrada.

- Permite evaluar los resultados obtenidos en base a multitud de criterios y directrices, desde la propia carta de Aalborg -que dio partida a la formulación del concepto de sostenibilidad urbana- hasta los recientes diecisiete Objetivos de Desarrollo Sostenible de la ONU.

- Ha sido elaborada por organismos que han tenido y/o tienen un papel relevante en el establecimiento de políticas urbanas sostenibles que se han extendido como directrices a nivel europeo.

\subsection{Criterios para la aplicación de la herramienta al caso de estudio escogido (Lucena, Córdoba)}

A continuación, se exponen los criterios tenidos en cuenta para la elección del caso de Lucena para la aplicación de la herramienta RFSC:

- Es una ciudad media que cumple con las definiciones tanto funcionales como numéricas enunciadas para el establecimiento de esta categoría urbana a nivel nacional y europeo.

- Pertenece a un conjunto territorial de ciudades medias con las que establece sinergias de cooperación destinadas, entre otros asuntos, a la mejora de su enfoque sostenible integrado.

- Es una de las escasas ciudades medias españolas que ha elaborado un segundo plan estratégico tras el éxito de la puesta en marcha y evaluación del primero, lo que permite la evaluación del cambio efectuado en las políticas de planificación urbana durante las últimas décadas, coincidiendo con las horquillas temporales que los propios principios de sostenibilidad e instrumentos para su evaluación han manejado.

- Mantiene un papel activo en la puesta en cuestión de la sostenibilidad y la estrategia integrada de su planificación. Prueba de ello es que sea actualmente la única ciudad media española -no capital de provincia- que participa anualmente en Ebrópolis, el Encuentro de Planes Estratégicos Urbanos y Territoriales que organiza la ciudad de Zaragoza y que en el año 2017 ha tenido su XIX edición, lo que muestra su interés por la actualización de sus políticas urbanas.

- La propia ciudad ha mostrado su interés por el Desarrollo Urbano Sostenible Integrado, así como por el Marco de Referencia para Ciudades Sostenibles mediante la organización de eventos de carácter internacional: una sesión RFSC Training Workshop con la participación de ICLEl y la propia oficina de Secretariado de RFSC en 2015, así como unas Jornadas sobre Políticas de Regeneración Urbana en 2015.

Dados los hechos expuestos, se decide aplicar la herramienta RFSC a los dos Planes Estratégicos de Lucena, con el objeto de comprobar su utilidad y, además, de observar la evolución en la perspectiva de desarrollo sostenible integrado entre ambos documentos de planificación.

A efectos del presente estudio, la herramienta ha sido aplicada sobre ambos planes en su apartado de evaluación, y más concretamente en la medición de la prioridad que, para cada plan estratégico, se ha otorgado a cada uno de los treinta objetivos que el Marco de Referencia para Ciudades Sostenibles establece dentro de las cinco dimensiones fundamentales.

La evaluación de RFSC define, para cada objetivo, unas condiciones de cumplimiento y relevancia del mismo, así como la posibilidad de asignar un nivel de prioridad del proyecto asociado al mismo entre cuatro: insignificante, baja, media y alta. La traslación del contenido de los planes a una evaluación ha exigido una labor de cuantificación de dicha prioridad, que finalmente se ha acordado definir mediante el número de proyectos (en el primer plan, de un total de cincuenta y cinco) o actuaciones (en el segundo plan, de un total también de cincuenta y cinco) que se alinean con el objetivo en cuestión.

De este modo, se ha establecido el siguiente rango: nivel 1 (insignificante), ningún proyecto; nivel 2 (baja), un proyecto; nivel 3 (media), dos proyectos; nivel 4 (alta), tres o más proyectos (o acciones en el caso del segundo plan) cuyo objetivo se relaciona con el indicado en el RFSC.

A continuación, se aplica la metodología mencionada sobre el Primer y Segundo Plan Estratégico de Lucena, para la obtención de los correspondientes resultados y conclusiones. 
GAPP. Nueva Época - N. 20, noviembre 2018 - ISSN: 1989-8991 - DOI: 10.24965/gapp.v0i20.10481 - [Págs. 143-163] Número monográfico - Gobernanza y políticas de desarrollo urbano: teoría y práctica

Planeamiento estratégico local y evaluación del desarrollo urbano sostenible integrado en ciudades medias Blanca del Espino Hidalgo / Daniel Navas Carrillo

\section{RESULTADOS}

\subsection{Aplicación de la herramienta RFSC al primer Plan Estratégico de Lucena}

El primer Plan Estratégico de Lucena se elabora en el año 2002, respondiendo a la necesidad de establecer una hoja de ruta para el crecimiento de la ciudad que, en ese momento, presentaba altos niveles de pujanza económica y demográfica en ese momento (Ayuntamiento de Lucena, 2002: IV.10) debidos, en gran parte, a la buena situación de un sistema productivo local basado en la industria y, más concretamente, en la producción del mueble de madera y del frío industrial (Caravaca et al., 2002: 180). El instrumento estuvo vigente hasta la elaboración, en 2015, del Segundo Plan Estratégico de Lucena, etapa durante la cual más de un $90 \%$ de sus proyectos ${ }^{3}$ se cumplimentaron satisfactoriamente (J. A. F., 2014).

Según el capítulo III del documento del Plan (Ayuntamiento de Lucena, 2002: III), la metodología incluyó, entre las fases de diagnóstico, de propuestas y de impulso, los informes de expertos, análisis de datos estadísticos, encuestas ciudadanas, entrevistas DELPHI y la elaboración de una matriz de actores. En todos los casos, resulta fundamental el criterio interno del Ayuntamiento de cara a posicionar y encauzar las vías de comunicación con los ciudadanos interesados en la participación. Finalmente, se celebró una conferencia estratégica. No obstante, el documento del plan no cuantifica numéricamente ni caracteriza de manera temática los participantes en el mismo, lo que impide determinar con certeza cuáles son los agentes configuradores del mismo.

El elenco de acciones a desarrollar (denominadas proyectos) se agrupaba en dieciocho programas de actuación y éstos, a su vez, en cinco líneas estratégicas (Ayuntamiento de Lucena, 2002: Cap. VI.1). De cara a la aplicación de la herramienta RFSC en este trabajo, la unidad escogida para el cómputo de acciones y el establecimiento del grado de prioridad asociado a cada uno de los objetivos de la herramienta será el de proyecto, con un total de cincuenta y cinco. Tan sólo tres objetivos tuvieron la máxima prioridad, mostrada por la aplicación de tres o más proyectos, mientras que otros ocho mostraron una prioridad nula al no asociarles ninguno de los proyectos del Plan (Tabla 1).

TABLA 1. ESTABLECIMIENTO DE PRIORIDADES DE LOS OBJETIVOS DE LA HERRAMIENTA RFSC, CON VALORES DE 1 (IRRELEVANTE) A 4 (ALTA), EN EL PRIMER PLAN ESTRATÉgICO DE LUCENA

\begin{tabular}{|c|c|}
\hline \multicolumn{2}{|r|}{ Dimensión espacial } \\
\hline 1 & Desarrollar una planificación urbana y de uso del suelo sostenibles \\
\hline 2 & Asegurar la equidad espacial \\
\hline 3 & Fomentar la resiliencia territorial \\
\hline 4 & Preservar y promover el patrimonio arquitectónico, cultural y urbano \\
\hline 5 & Promover la calidad y funcionalidad de los espacios públicos y ambientes \\
\hline 6 & Desarrollar la movilidad alternativa y sostenible \\
\hline \multicolumn{2}{|r|}{ Gobernanza } \\
\hline 7 & Asegurar una estrategia territorial integrada \\
\hline 8 & Fomentar la administración y gestión financiera sostenibles \\
\hline 9 & Implementar un proceso de evaluación y mejora continua \\
\hline 10 & Incrementar la participación ciudadana \\
\hline 11 & Fortalecer la gobernanza colaborativa \\
\hline 12 & Facilitar el desarrollo de capacidades y creación de redes \\
\hline
\end{tabular}

3 Según declaraciones del alcalde de la ciudad en un periódico provincial publicadas por J. A. F., 2014. 


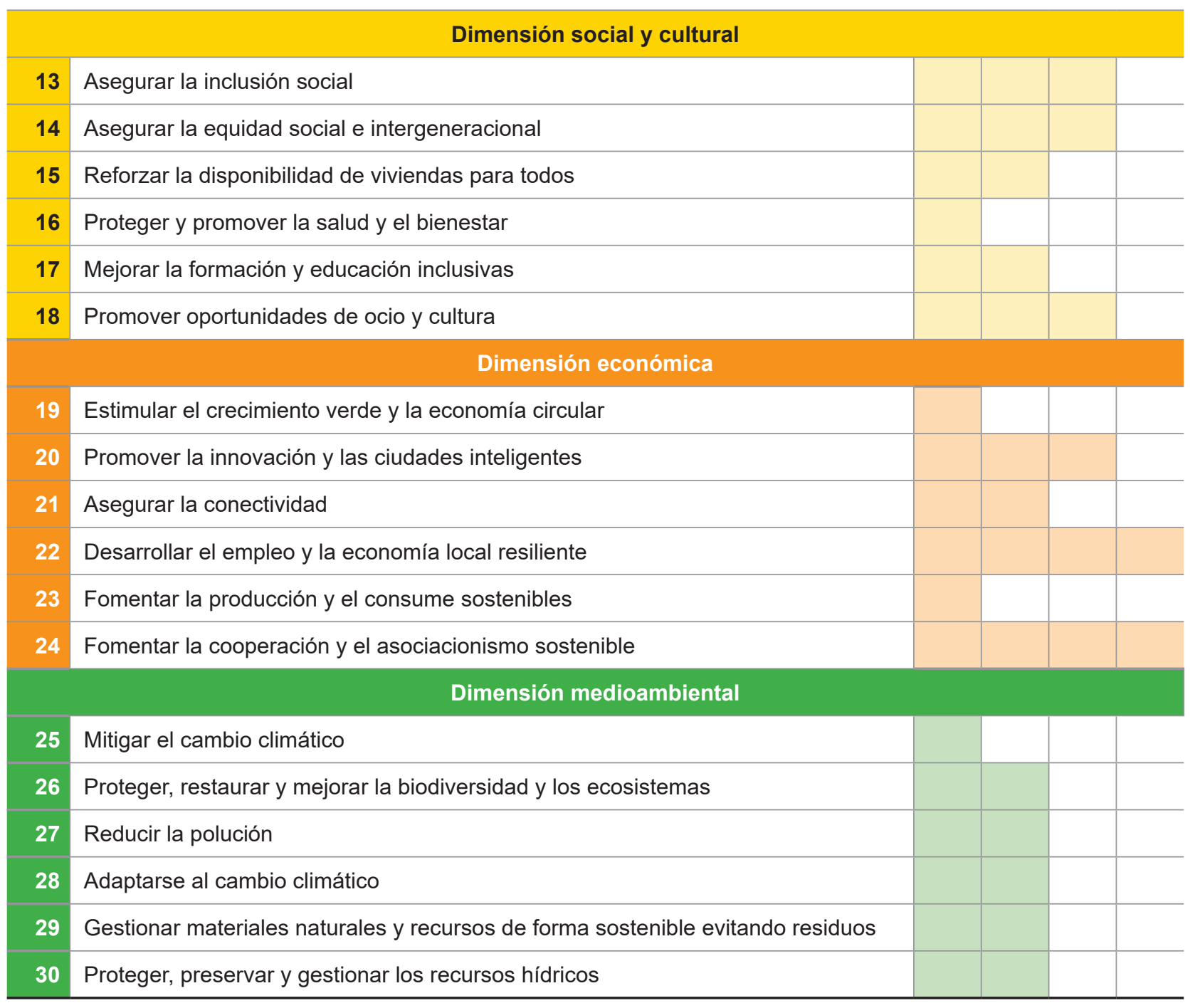

El equilibrio y carácter integrado del Plan puede observarse, en primera instancia, mediante la obtención de una gráfica radial que integra los resultados obtenidos en función de las cinco dimensiones que el propio RFSC (Figura 1). Se detecta una clara inclinación hacia las dimensiones económica, espacial y social, mientras que la medioambiental y la de gobernanza quedan relegadas a un segundo plano, especialmente esta última, que cuenta con pocos proyectos dedicados a mejorar los procesos de toma de decisiones en la ciudad por parte de la ciudadanía.

Resultados similares se extraen de la obtención de resultados organizados en función a los cuatro pilares clásicos de la sostenibilidad (Figura 2). Al no considerarse la dimensión espacial que estaba presente en los objetivos RFSC, se identifica una clara inclinación del Plan hacia el ámbito económico y, en un segundo plano, hacia el social, mediante que el ambiental y de gobernanza siguen ocupando, respectivamente, el tercer y cuarto puestos.

El sistema de evaluación difiere sustancialmente de los anteriores al centrarnos en los principios de la Carta de Aalborg (Figura 3), en los que desaparecen los grandes ámbitos temáticos y se establece una escalera de color que alude a diez diferentes aspectos de la sostenibilidad. El resultado de este análisis, si bien es más complejo en su aprehensión mediante un golpe de vista, permite obtener conclusiones pormenorizadas como, por ejemplo, la importancia otorgada a la calidad de vida de los habitantes o al buen tono de la economía local.

La norma ISO 37101 añade una visión distinta de la evaluación que se centra principalmente en el resultado de las acciones sobre las comunidades ciudadanas. Así, su análisis basado en seis temáticas principa- 
les muestra fundamentalmente una inclinación del Plan hacia el atractivo de la ciudad y, en segundo lugar, hacia el bienestar. En un siguiente estrato quedaría la cohesión social y, en último lugar, los ámbitos destinados a la preservación y mejora del medio ambiente, la resiliencia o el uso responsable de los recursos.

Llama la atención, en este caso, la desaparición del concepto de gobernanza entre las cuestiones a analizar y, por el contrario, el aumento de aspectos relacionados con el medio, por lo que los resultados aparecen mucho más claramente polarizados entre dos ámbitos a los que se otorgan pesos visiblemente diferentes.

\section{FiguRA 1. EVALUACIÓN DEL PRIMER PLAN ESTRATÉGICO DE LUCENA SEgÚN LAS CINCO DIMENSIONES PARA EL ANÁLISIS INTEGRADO DEL MARCO DE REFERENCIA PARA CIUDADES SOSTENIBLES}

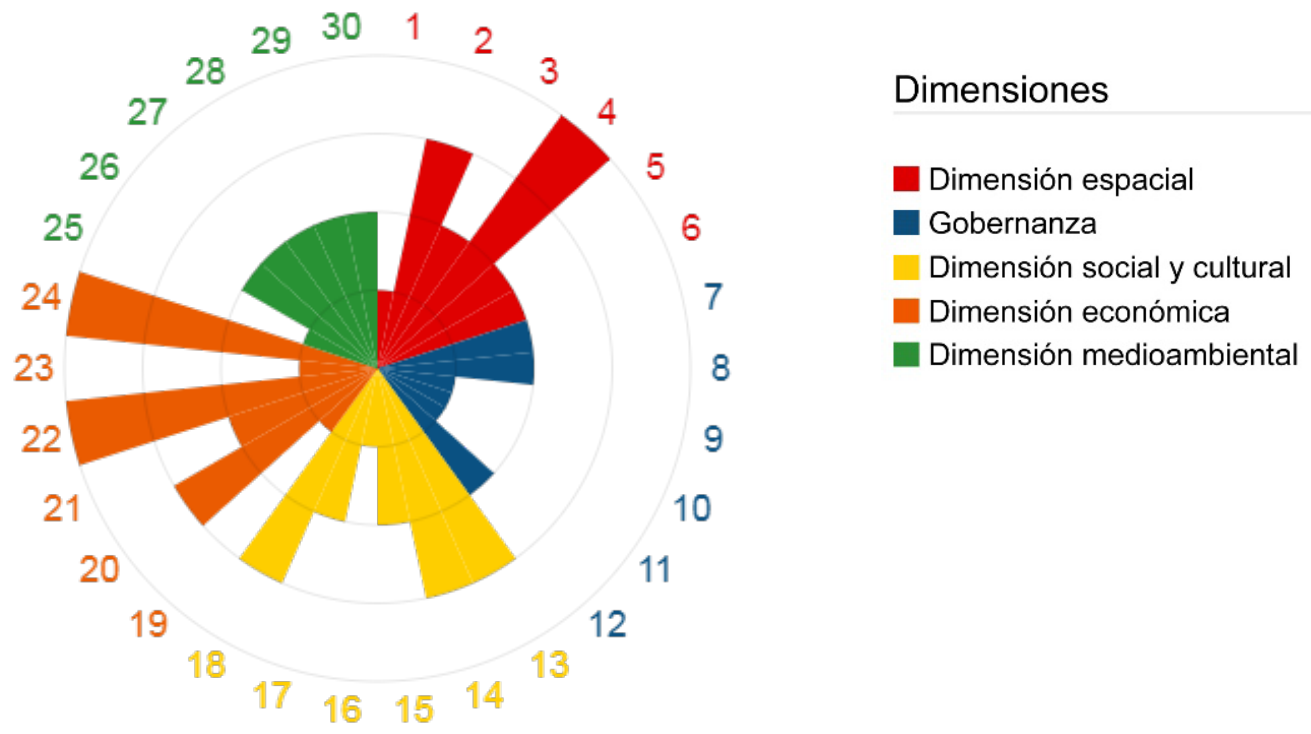

Fuente: Elaboración propia sobre herramienta de evaluación RFSC.

FiguRA 2. EVALUACIÓn DEL PRIMER PLAN ESTRATÉGICO DE LUCENA SEGÚN LOS CUATRO PILARES CLÁSICOS DE LA SOSTENIBILIDAD

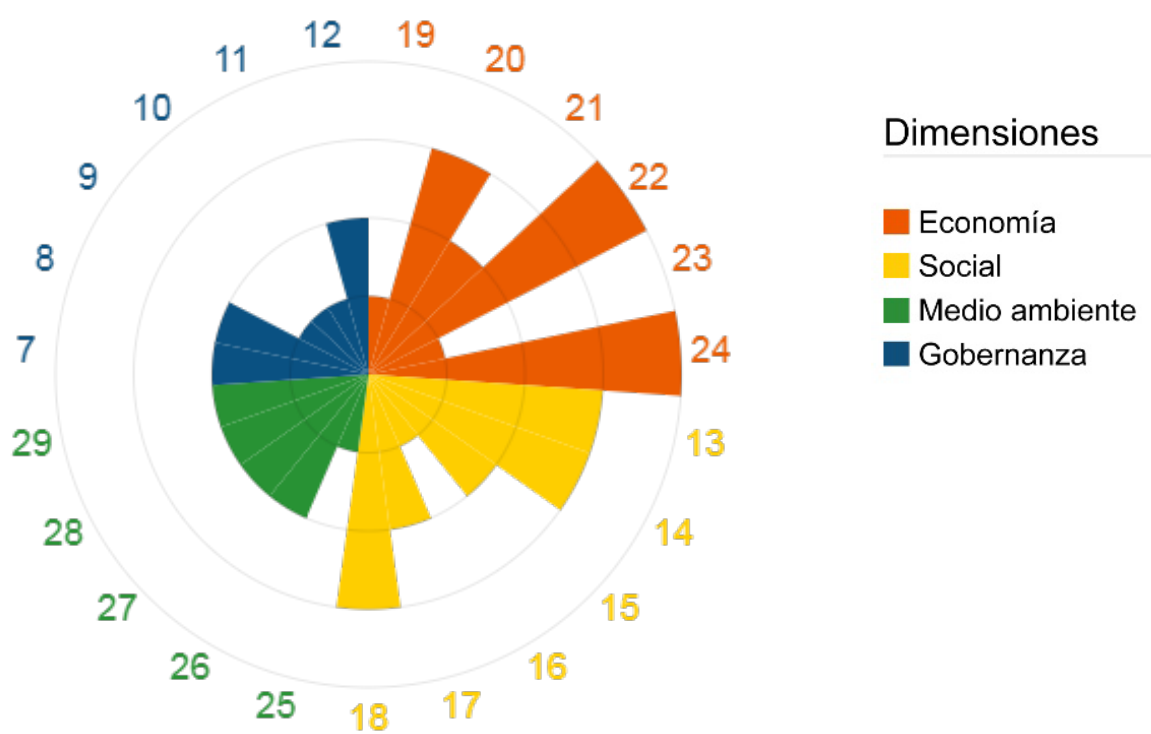

Fuente: Elaboración propia sobre herramienta de evaluación RFSC. 
GAPP. Nueva Época - N. 20, noviembre 2018 - ISSN: 1989-8991 - DOI: 10.24965/gapp.v0i20.10481 - [Págs. 143-163] Número monográfico - Gobernanza y políticas de desarrollo urbano: teoría y práctica

Planeamiento estratégico local y evaluación del desarrollo urbano sostenible integrado en ciudades medias

Blanca del Espino Hidalgo / Daniel Navas Carrillo

Figura 3. eVAlUACión del PRIMER PLAN ESTRATÉGico de LUCENA

SEGÚN LOS PRINCIPIOS DE LA CARTA DE AALBORG

DE LAS CIUDADES EUROPEAS HACIA LA SOSTENIBILIDAD

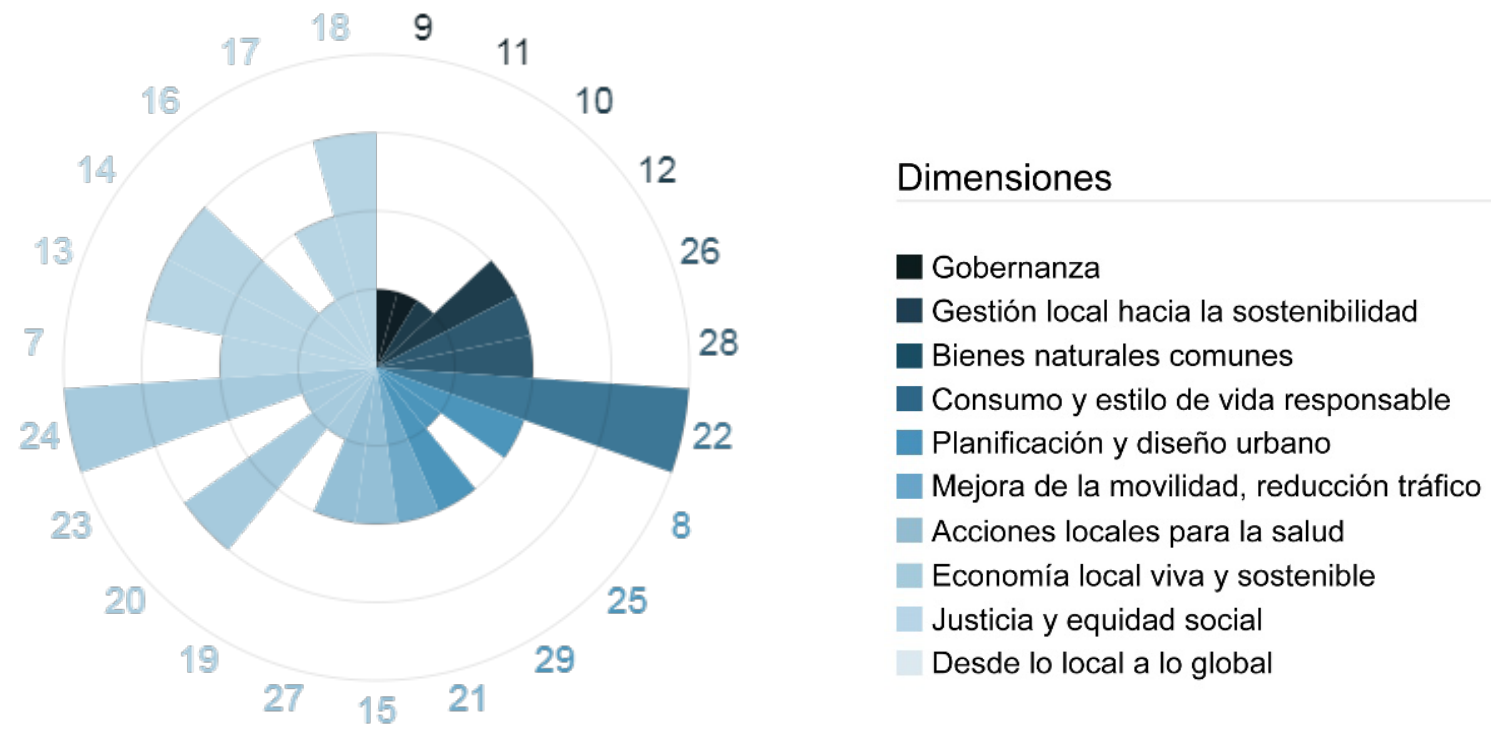

Fuente: Elaboración propia sobre herramienta de evaluación RFSC.

FIGURA 4. EVALUACIÓN DEL PRIMER PLAN ESTRATÉGICO DE LUCENA

SEGÚN LOS PROPÓSITOS DE LA NORMA ISO 37101

SOBRE EL DESARROLLO SOSTENIBLE DE LAS COMUNIDADES

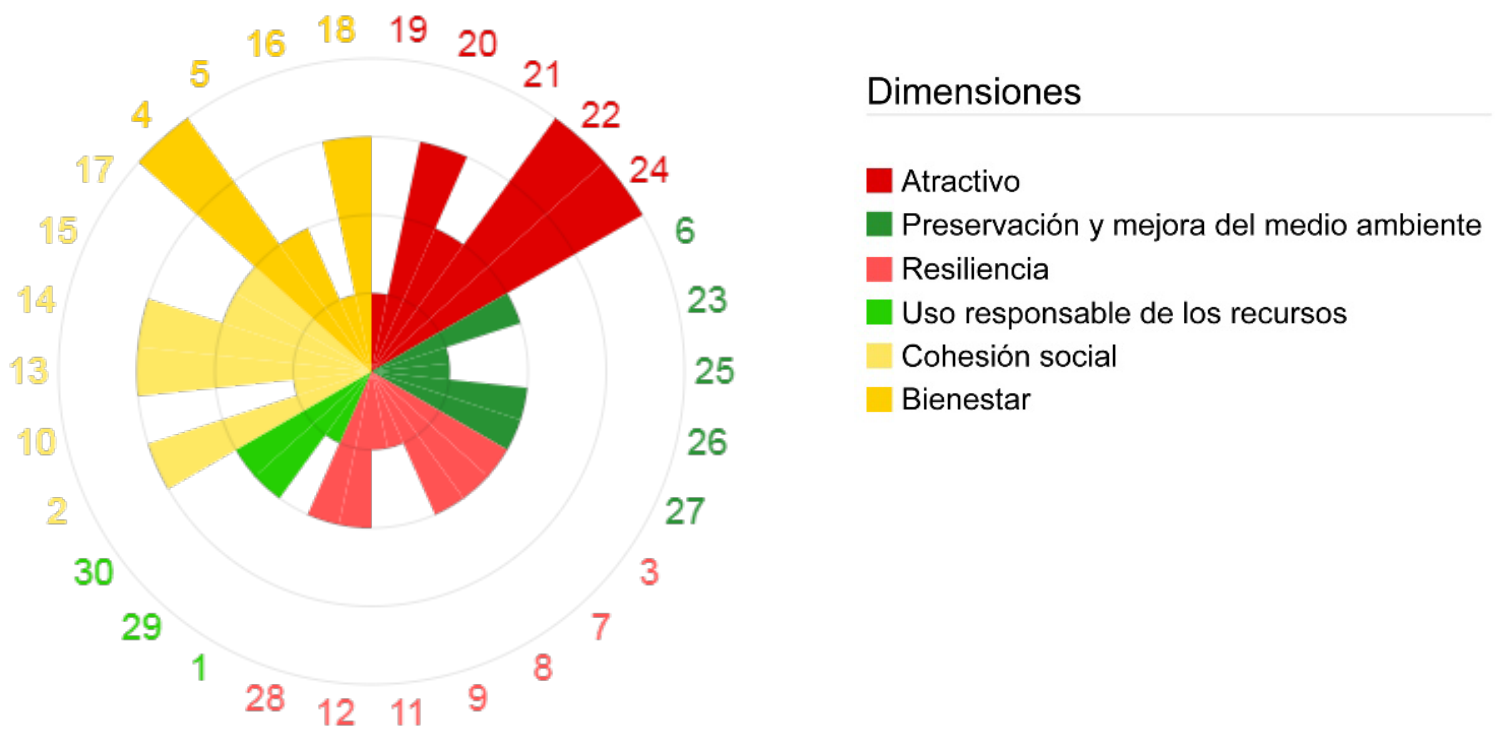

Fuente: Elaboración propia sobre herramienta de evaluación RFSC. 
GAPP. Nueva Época - N. 20, noviembre 2018 - ISSN: 1989-8991 - DOI: 10.24965/gapp.v0i20.10481 - [Págs. 143-163] Número monográfico - Gobernanza y políticas de desarrollo urbano: teoría y práctica

\subsection{Aplicación de la herramienta RFSC al segundo Plan Estratégico de Lucena}

TABLA 2. ESTABLECIMIENTO DE PRIORIDADES DE LOS OBJETIVOS DE LA HERRAMIENTA RFSC, CON VALORES DE 1 (IRRELEVANTE) A 4 (ALTA), EN EL SEGUNDO PLAN ESTRATÉGICO DE LUCENA

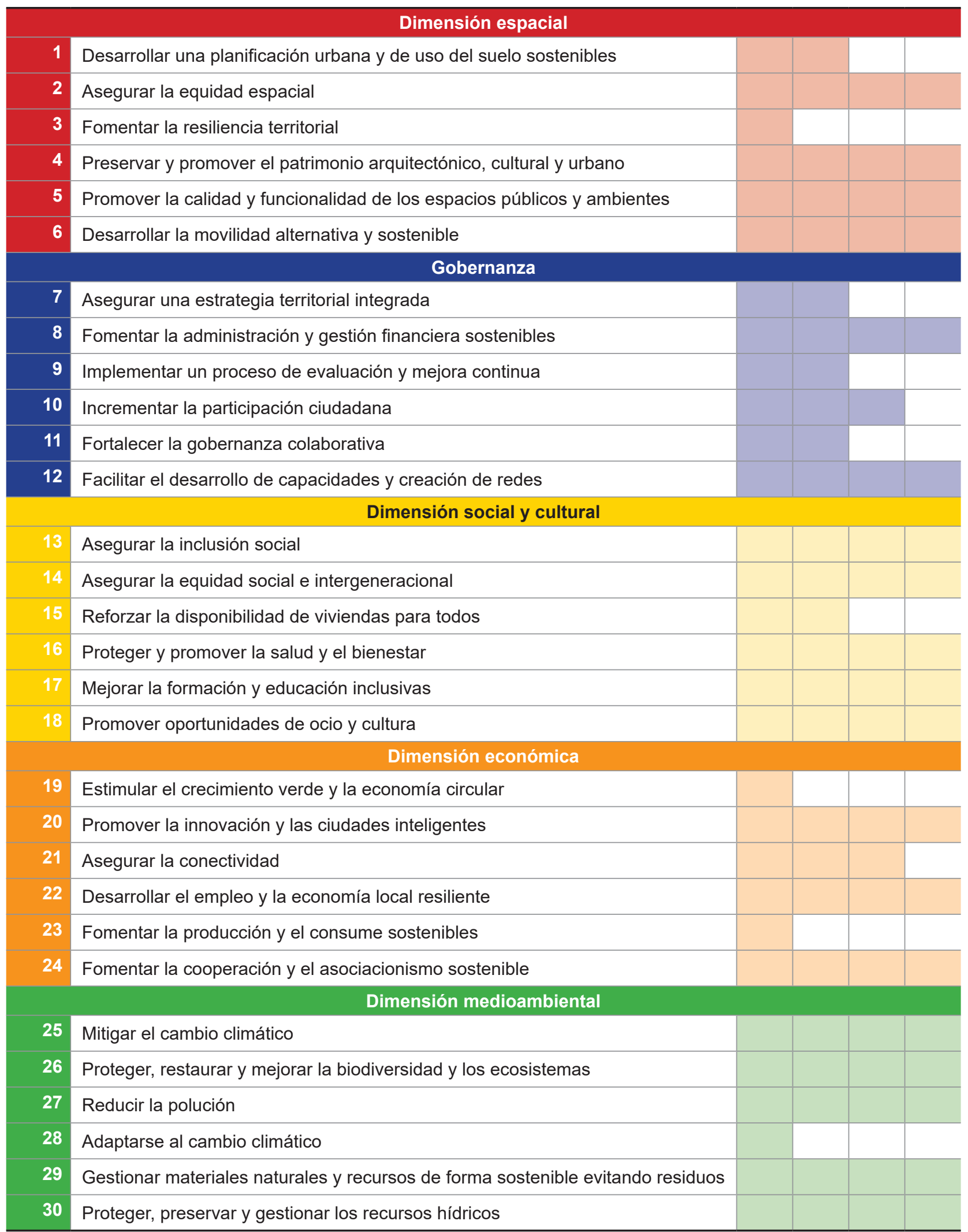


El segundo Plan Estratégico de Lucena se elabora en el año 2015 en base a la experiencia previa devenida del desarrollo del primer plan y asumiendo las innovaciones implementadas en los planes estratégicos urbanos de los últimos años como consecuencia de los cambios producidos en los modelos de gestión de las ciudades, especialmente en lo referente a la gobernanza. Con estas premisas, el Segundo Plan Estratégico busca dar respuesta a «tres grandes elementos que están condicionando el éxito en los procesos de transformación urbana en el Siglo XXI: la capacidad de articular redes de actores urbanos, el proyecto como instrumento de transformación y el carácter innovador de las propuestas de intervención» (Ayuntamiento de Lucena, 2015: 8).

Según el documento de elaboración del propio Plan (Ayuntamiento de Lucena, 2015: 85), el proceso de elaboración de diagnóstico partía de datos secundarios cuantitativos que fueron cualificados mediante la elaboración de encuestas a la ciudadanía y de entrevistas de profundidad a expertos de diferentes ámbitos de la ciudad, lo que dio lugar a un diagnóstico basado en 17 hechos agrupados en 5 grandes retos (movilidad, barrios, educación, economía y cultura-creatividad). Posteriormente, se celebraron 10 grupos de trabajo temáticos con 15 participantes cada uno y encabezados por 10 líderes ciudadanos, en los que se hicieron propuestas para dar respuesta a estos retos, recogiéndose un total de 170 propuestas que fueron priorizadas en un foro ciudadano con la participación de 200 personas. Finalmente, el Plan fue ratificado en Pleno municipal con la unanimidad de los cinco partidos políticos que lo componían. La cantidad y diversidad de actores implicados en la elaboración del Segundo Plan Estratégico de Lucena pone de manifiesto un cambio de paradigma en los procesos de planificación local que veníamos adelantando en el cuerpo teórico y que, por otra parte, ha sido auspiciado por las directrices nacionales e internacionales.

Como ocurría en el primer caso, los objetivos del Plan se corresponden en último nivel con cincuenta y cinco acciones, las cuales servirán de base para aplicar la herramienta RFSC al conjunto de este plan. Aunque no tiene influencia sobre el proceso de evaluación, cabe mencionar que su estructura difiere sustancialmente de la del anterior, al quedar las acciones agrupadas en veinticinco líneas de actuación y estas, a su vez, en siete proyectos estratégicos.

En la tabla 2 se observa que, del total de treinta objetivos, diecinueve obtuvieron la máxima prioridad -se recuerda que este nivel se corresponde con objetivos contemplados en tres o más acciones del plan-. Por el contrario, solo cuatro de los objetivos no se han podido vincular con alguna de las cincuenta y cinco acciones del Plan, correspondiendo a una prioridad nula.

FIGURA 5. EVALUACIÓN DEL SEGUNDO PLAN ESTRATÉGICO DE LUCENA SEGÚN LAS CINCO DIMENSIONES PARA EL ANÁLISIS INTEGRADO DEL MARCO DE REFERENCIA PARA CIUDADES SOSTENIBLES

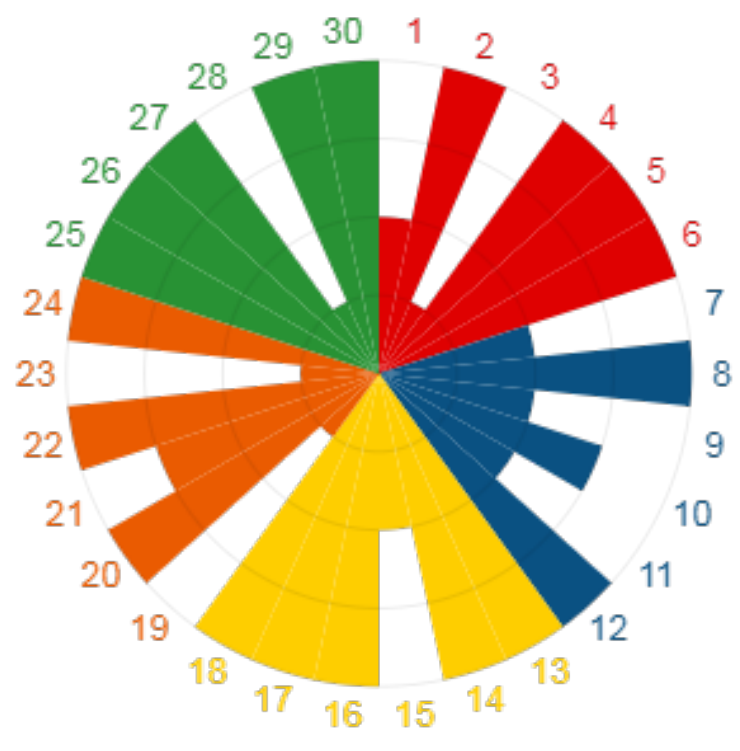

\section{Dimensiones}

Dimensión espacial

Gobernanza

Dimensión social y cultural

Dimensión económica

Dimensión medioambiental

Fuente: Elaboración propia sobre herramienta de evaluación RFSC. 


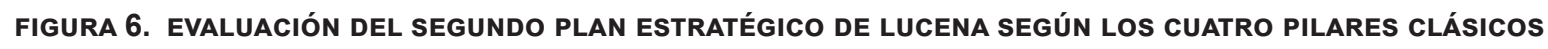
DE LA SOSTENIBILIDAD

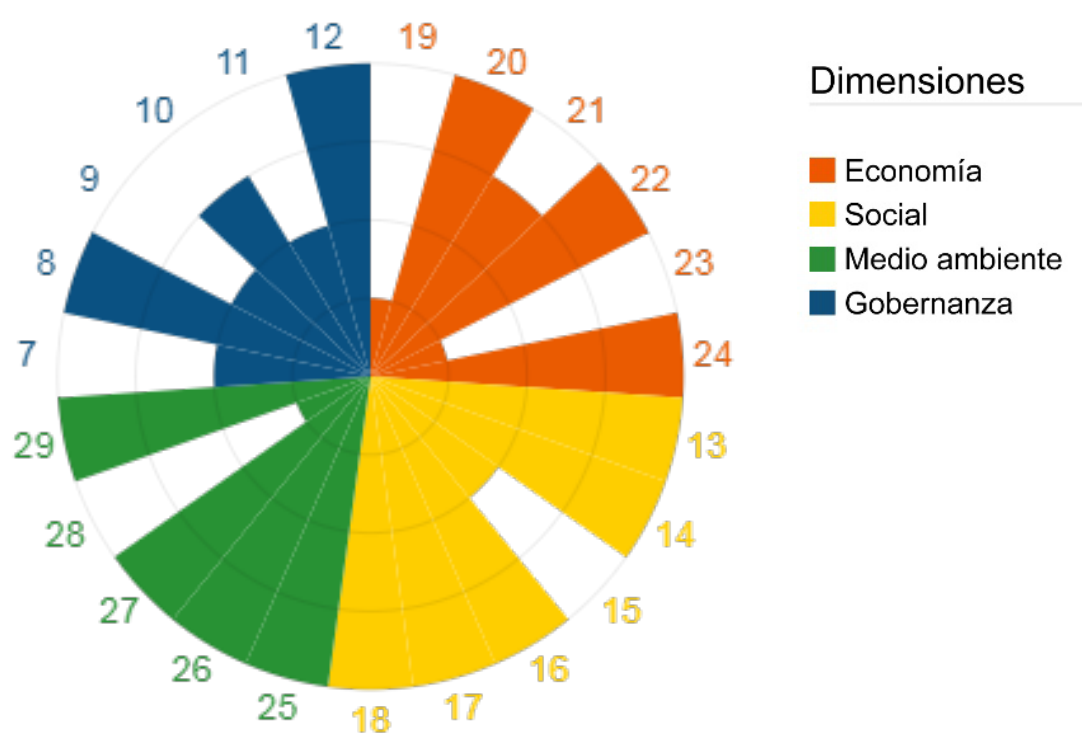

Fuente: Elaboración propia sobre herramienta de evaluación RFSC.

De las cinco dimensiones analizadas, los resultados representados en la figura 5 muestran que las acciones del segundo plan se alinean principalmente con las dimensiones socio cultural y medioambiental. En un segundo nivel de prioridad se sitúan las dimensiones económica y espacial en proporciones similares. Se advierte un relativo déficit de proyectos relacionados con los objetivos en materia de gobernanza, si bien se superan los datos del primero de los planes.

Si el análisis se basa en los cuatro pilares clásicos de la sostenibilidad (Figura 6), destacan nuevamente las dimensiones social y medioambiental, con unos niveles de prioridad -salvo en uno de los indicadores en cada caso- máximos. Seguidamente, la dimensión económica se sitúa como el tercero de los bloques en número de acciones del Plan que contribuyen a sus objetivos. Las consideraciones para los aspectos relativos a la gobernanza se mantienen, si bien el peso de este último es algo menor al haberse reducido de cinco a cuatro las temáticas analizadas.

FIGURA 7. EVALUACIÓN DEL SEGUNDO PLAN ESTRATÉGICO DE LUCENA SEGÚN LOS PRINCIPIOS DE LA CARTA DE AALBORG DE LAS CIUDADES EUROPEAS HACIA LA SOSTENIBILIDAD

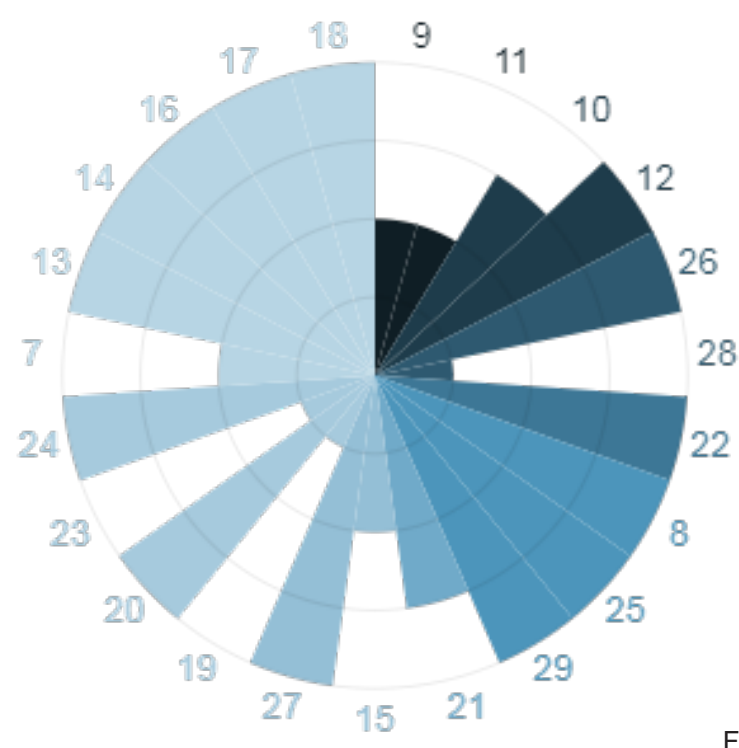

Fuente: Elaboración propia sobre herramienta de evaluación RFSC. 
En cuanto al análisis en base a los principios de la sostenibilidad recogidos en la Carta de Aalborg (Figura 7), se observa el peso que adquieren en el Plan las medidas que buscan justicia y equidad social, aunque hay que tener en cuenta que es el ámbito que está representado con mayor número de objetivos. Máxima prioridad se les otorga a las acciones relativas al planeamiento y el diseño urbano, o a las que tienen que ver con la calidad de vida de los habitantes, analizadas con tres y un indicador respectivamente. También se advierte el reducido número de acciones dirigidas a mejorar los mecanismos de toma de decisiones y el modelo de gestión de la ciudad.

Tal como se ha señalado, en la norma ISO 37101 las consecuencias directas sobre el ciudadano se sitúan en el centro del análisis. De los seis aspectos analizados, los resultados muestran que el Segundo Plan Estratégico de Lucena se caracterizaría por buscar, en primer lugar, el bienestar ciudadano. En niveles elevados -cuasi máximos-, este plan tendría como objetivo el atractivo de la ciudad, la cohesión social, la preservación y mejora del medio ambiente o el uso responsable de los recursos. En el lado contrario se situaría la resiliencia, que en gran medida está relacionada con la gobernanza, temática que desaparece de los bloques analizados en base a esta norma.

\section{FIGURA 8. EVALUACIÓN DEL SEgUNDO PLAN ESTRATÉGICO DE LUCENA SEgÚN LOS PROPÓSITOS DE LA NORMA ISO 37101 SOBRE EL DESARROLLO SOSTENIBLE DE LAS COMUNIDADES}

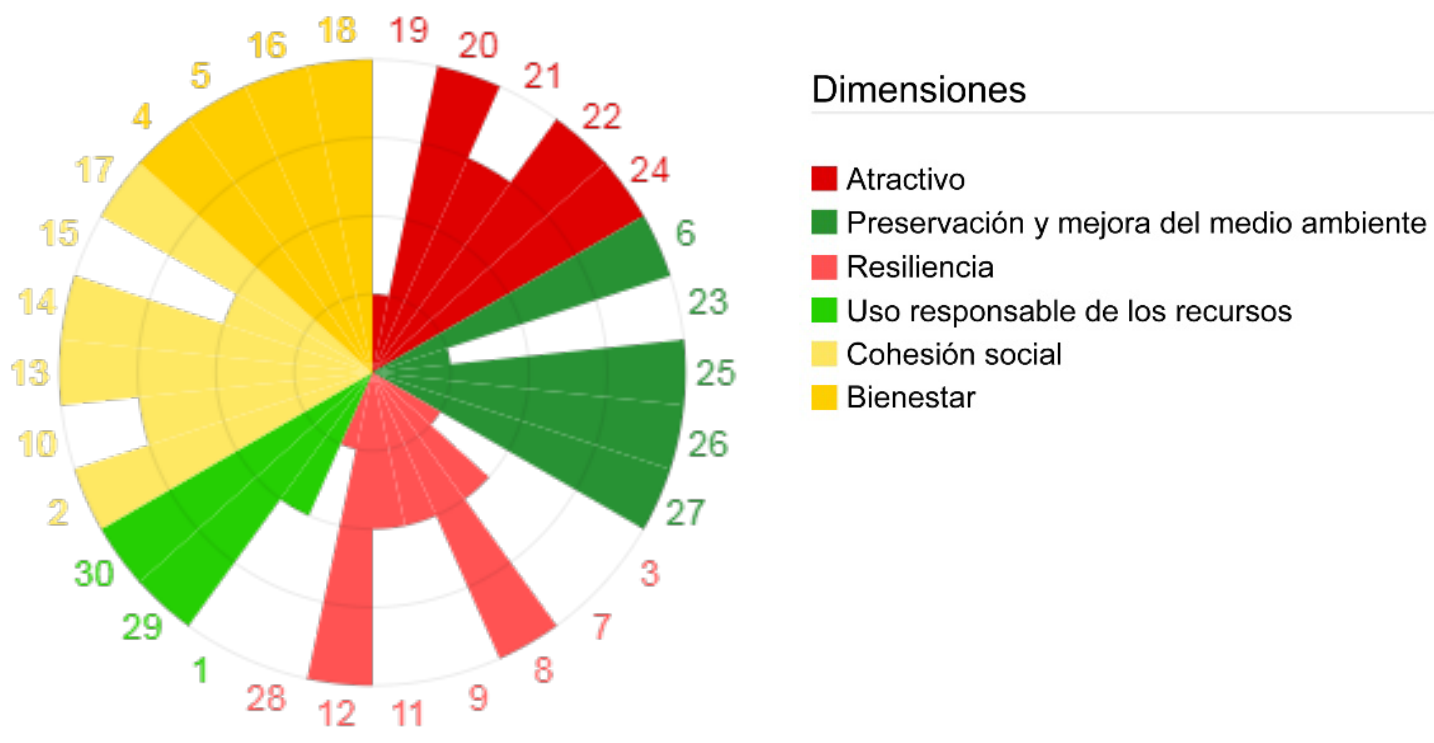

Fuente: Elaboración propia sobre herramienta de evaluación RFSC.

\section{DISCUSIÓN}

Los resultados de la aplicación de la herramienta RSFC a los dos panes estratégicos hasta el momento aprobados para la ciudad de Lucena han mostrado el carácter integrado de ambos, si bien para el segundo de ellos los resultados son notablemente mejores. En términos generales, la evaluación efectuada nos muestra que de un plan a otro se ha producido un avance significativo en los niveles de prioridad otorgados a los distintos objetivos analizados.

Tal como se ha comentado, en el primer plan son solo tres los objetivos con máxima prioridad, los cuales se mantienen en el segundo de los planes (4-Preservar y promover el patrimonio arquitectónico, cultural y urbano, 22-Crear empleo y una economía local resiliente y 24-Fomentar la cooperación y el asociacionismo innovador). Merece ser destacado que, en el segundo, este número aumenta considerablemente hasta un total de diecinueve indicadores. En términos porcentuales, estos datos representan el $10 \%$ y el $63 \%$ respectivamente. 
FIGURA 9. COMPARACIÓN DE LA EVALUACIÓN OBTENIDA EN EL PRIMER Y SEGUNDO PLAN ESTRATÉGICO DE LUCENA SEGÚN LAS CINCO DIMENSIONES PARA EL ANÁLISIS INTEGRADO DEL MARCO DE REFERENCIA PARA CIUDADES SOSTENIBLES

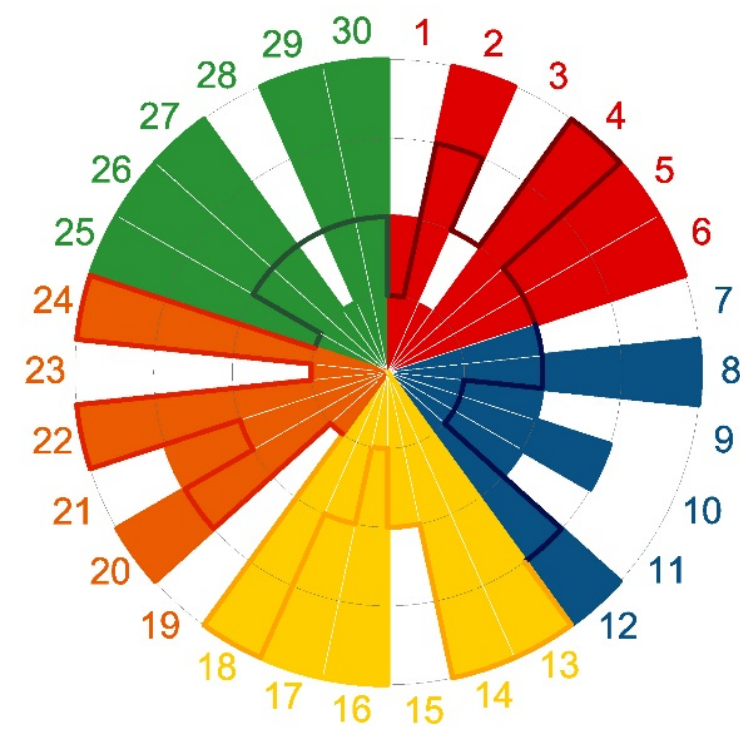

\section{Dimensiones}

Dimensión espacial

Gobernanza

Dimensión social y cultural

Dimensión económica

Dimensión medioambiental

Primer Plan

Segundo Plan

Fuente: Elaboración propia sobre herramienta de evaluación RFSC.

FIGURA 10. COMPARACIÓN DE LA EVALUACIÓN OBTENIDA EN EL PRIMER Y SEGUNDO PLAN ESTRATÉGICO DE LUCENA SEGÚN LOS CUATRO PILARES CLÁSICOS DE LA SOSTENIBILIDAD

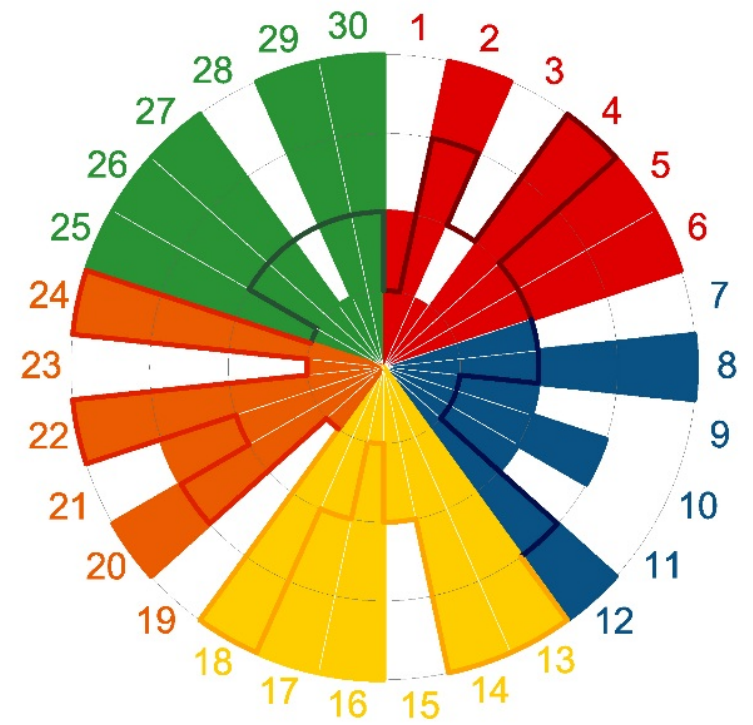

\section{Dimensiones}

Dimensión espacial

Gobernanza

Dimensión social y cultural

Dimensión económica

Dimensión medioambiental

Primer Plan

Segundo Plan

Fuente: Elaboración propia sobre herramienta de evaluación RFSC.

Por el contrario, de los ocho objetivos que fueron caracterizados con prioridad nula en el primer plan, solo dos indicadores siguen sin poder ser asociados a ninguno de los proyectos del Plan (19-Estimular el crecimiento verde y la economía circular y 23-Fomentar la producción y el consumo sostenibles). No son los únicos objetivos de nula prioridad, puesto que otros, inicialmente calificados con nivel 2, pasan al nivel inferior (3-Fomentar la resiliencia territorial, 28-Adaptarse al cambio climático). En este sentido, se consigue reducir del $27 \%$ al $13 \%$ el número de objetivos no considerados en el diseño de los planes. 
En el resto de niveles (2 y 3 ), el número de indicadores son respectivamente catorce $(47 \%)$ y cinco $(17 \%)$ en el primer plan, y cinco $(17 \%)$ y dos $(1 \%)$ en el segundo. Se observa cómo en ambos casos los datos son menores en el segundo de los planes, lo que atestigua que sus acciones responden a una distribución más integrada que en el primero. De todos ellos, únicamente un indicador (15-Reforzar la disponibilidad de viviendas para todos) tiene igual prioridad en ambos planes.

\section{FIGURA 11. COMPARACIÓN DE LA EVALUACIÓN OBTENIDA EN EL PRIMER Y SEGUNDO PLAN ESTRATÉGICO DE LUCENA} SEGÚN LOS PRINCIPIOS DE LA CARTA DE AALBORG DE LAS CIUDADES EUROPEAS HACIA LA SOSTENIBILIDAD

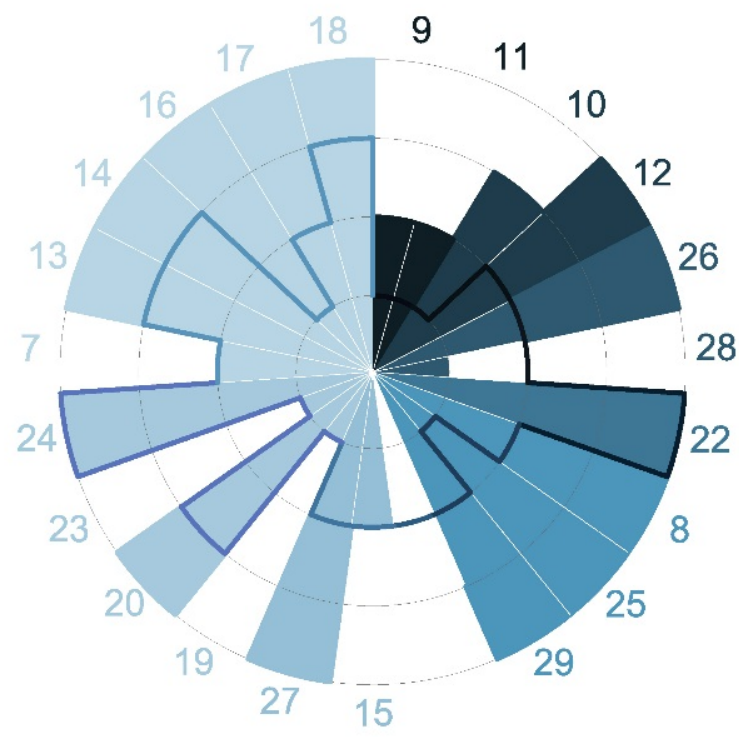

\section{Dimensiones}

Gobernanza

Gestión local hacia la sostenibilidad

Bienes naturales comunes

Consumo y estilo de vida responsable

Planificación y diseño urbano

Mejora de la movilidad, reducción tráfico

Acciones locales para la salud

Economía local viva y sostenible

Justicia y equidad social

Desde lo local a lo global

Primer Plan

Segundo Plan

Fuente: Elaboración propia sobre herramienta de evaluación RFSC.

FIGURA 12. COMPARACIÓN DE LA EVALUACIÓN OBTENIDA EN EL PRIMER Y SEGUNDO PLAN ESTRATÉGICO DE LUCENA SEGÚN LOS PROPÓSITOS DE LA NORMA ISO 37101 SOBRE EL DESARROLLO SOSTENIBLE DE LAS COMUNIDADES

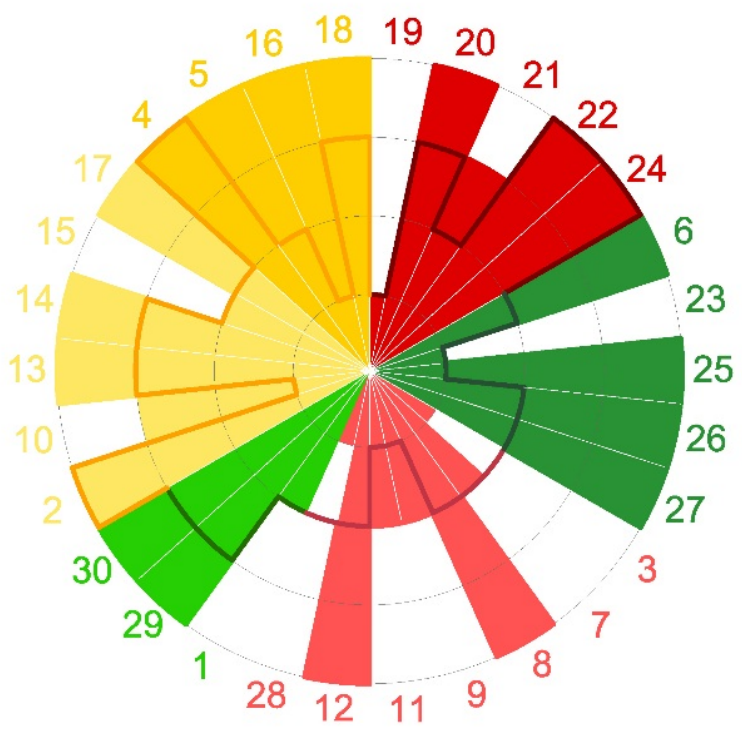

\section{Dimensiones}

Atractivo

Preservación y mejora del medio ambiente

Resiliencia

Uso responsable de los recursos

Cohesión social

Bienestar

Primer Plan

Segundo Plan

Fuente: Elaboración propia sobre herramienta de evaluación RFSC.

Son igualmente destacables las conclusiones que pueden extraerse de la caracterización de la variación experimentada. Como se ha indicado, dos indicadores (7\%) han visto reducida su prioridad, y siete (23\%) 
se han mantenido constantes, dos en nivel 1, otro en nivel 2, y el resto en el máximo nivel. En este sentido, solo hay tres objetivos $(30 \%)$ a los que se les podía haber dado mayor prioridad en el segundo plan, y no se ha hecho. En unas proporciones similares, se detectan nueve objetivos $(30 \%)$ que han visto aumentado su prioridad en un nivel y diez (33\%). que incrementan en dos grados. Solo dos de los indicadores $(7 \%)$ pasan de mínima o máxima prioridad.

Consecuentemente, la valoración en cuanto a la distribución por bloques en los distintos modelos analizados también mejora considerablemente. Ahora bien, cabe realizar algunas matizaciones con objeto a implementar medidas complementarias al segundo plan. En el primer plan se detectaba una clara inclinación hacia las dimensiones económica, espacial y social, frente a la medioambiental y la de gobernanza. En el segundo, los aspectos relativos a la economía, aunque mejoran en términos cuantitativos, pierden peso a favor del resto de dimensiones, especialmente en lo relativo a lo medioambiental. Es precisamente este el bloque temático que mayor mejora presenta, con indicadores que no superaban el nivel 2 en el primero de los planes que pasan a adquirir, salvo en un caso, máxima prioridad.

Mención aparte merece el análisis de la gobernanza. Se trata del bloque temático que presenta peores resultados en ambos planes, si bien cabe destacar que se consigue mejorar sustancialmente con respecto al primer plan. Probablemente, el propio contraste entre las dos metodologías adoptadas (entre las cuales se identifica una mejora sustancial en cuanto a la identificación y cuantificación de actores y los procesos de participación ciudadana) sea relevante en cuanto al resultado final en términos de gobernanza y, a su vez, un reflejo de la evolución que han tenido las herramientas de planificación urbana en términos participativos en la última década.

De forma general, la investigación ha detectado un especial déficit en dos tipos de acciones. En primer lugar, las que se refieren a acciones que superan los límites urbanos de la ciudad en las que se observa que, si bien hay un intento de coordinación con las administraciones de rango superior, ambos planes vienen a responder a las competencias propias de la municipalidad. En este sentido, las posibilidades de mejora son limitadas. Por otro lado, las relacionadas con el concepto de resiliencia que se recoge como uno de los bloques del modelo de análisis en base la norma ISO 37101. A este respecto, cuestiones como el crecimiento verde, la economía circular, la capacidad de adaptación al cambio climático y, especialmente, los indicadores que tienen que ver con la gobernanza deberán ser objetivos a tener en cuenta en futuras revisiones del plan vigente o dado el caso, en la redacción de uno nuevo.

En cuanto a la utilidad de la propia herramienta y la fiabilidad de los resultados obtenidos para la evaluación de otros proyectos y planes que tengan el desarrollo urbano sostenible integrado entre sus principios, habría que comenzar haciendo alusión al criterio utilizado para discernir si cada uno de los proyectos analizados contribuye a la consecución de un objetivo de los indicados por la herramienta. En este sentido, debe aclararse en primer lugar que, a falta de datos objetivos o indicadores que expresamente arrojen resultados sobre el mismo, la decisión depende exclusivamente de los técnicos que apliquen la herramienta (en este caso, los autores del artículo) quienes, en base al conocimiento de los contenidos del plan y de la descripción de cada una de las propuestas y acciones incluidas en el mismo, tratarán de discernir la persecución o no de cada uno de los objetivos RFSC con el mayor grado de objetividad posible, sin que ello sea garante de la ausencia de cierto sesgo en la aplicación. En casos extremos, la utilización de la herramienta RFSC como demostración del carácter integrado para potenciales promotores de proyectos y planes, podría conllevar la aplicación de un grado de subjetividad consciente a favor de ciertos resultados, lo que limita la aplicación del sistema con garantías.

En este sentido, se advierte que, de haber tratado de aplicar en un sentido similar la herramienta de evaluación del impacto que tiene cada una de las propuestas sobre el resto, también disponible en la plataforma RFSC, la discrecionalidad de la toma de decisiones habría sido similar o incluso mayor, dado que este proceso sería muy difícilmente abarcable para técnicos externos o investigadores que no hayan participado del proceso de puesta en carga del propio plan. No ocurre así, sin embargo, con la batería de indicadores que la herramienta pone a disposición del usuario, que sí cuentan con parámetros mensurables en base a datos objetivos. No obstante, esto vuelve a incidir en la mencionada dificultad de establecer indicadores cualitativos y la tendencia imperante a los indicadores cuantitativos como base de evaluación.

Por último, la disponibilidad de tiempo y espacio para la redacción de este trabajo ha limitado las posibilidades de atender a la aplicación de las distintas propuestas en cuanto a su implementación en el territorio o la distribución espacial en la ciudad, particularmente respecto a las características del tejido urbano y la población residente y usuaria de las distintas áreas. Así pues, el análisis de integralidad de las acciones previstas dentro de cada uno de los planes se ha realizado en términos absolutos, es decir, ha sido abordado 
GAPP. Nueva Época - N. 20, noviembre 2018 - ISSN: 1989-8991 - DOI: 10.24965/gapp.v0i20.10481 - [Págs. 143-163] Número monográfico - Gobernanza y políticas de desarrollo urbano: teoría y práctica

Planeamiento estratégico local y evaluación del desarrollo urbano sostenible integrado en ciudades medias Blanca del Espino Hidalgo / Daniel Navas Carrillo

para el conjunto de la ciudad de Lucena. Este aspecto se advierte como futura línea de investigación que completaría las conclusiones hasta el momento obtenidas.

\section{REFERENCIAS BIBLIOGRÁFICAS}

AENOR (2016), Norma ISO 37101 para la gestión sostenible de las comunidades. En línea: https://www.iso.org/ standard/61885.html (consulta: 10 de julio de 2017).

AYUNTAMIENTO DE LUCENA (2002), Plan Estratégico de Lucena. En línea: http://s409804199.mialojamiento.es/1erplan-estrategico (consulta: 10 de julio de 2017).

AYUNTAMIENTO DE LUCENA (2015), Segundo Plan Estratégico de Lucena. Agenda Estratégica Integrada de Desarrollo Urbano Sostenible (2015-2025). En línea: https://www.aytolucena.es/sites/default/files/segundo_plan_ estrategico_de_lucena.pdf (consulta: 11 de julio de 2017).

BARTON, J. R. (2006), "Sustentabilidad urbana como planificación estratégica". EURE-Revista Latinoamericana de Estudios Urbanos Regionales, vol. 32, núm. 96, págs. 27-46. DOI: https://doi.org/10.4067/s025071612006000200003

BELLET SANFELIU, C. y BELTRÃo SPOSITO, M. E. (2009), Las ciudades medias o intermedias en un mundo globalizado. Lleida: Universitat de Lleida.

BELLET SANFELIU, C. y LLOP TORNÉ, J. M. (1999), Ciudades Intermedias y Urbanización Mundial. Lleida: UNESCO, Ayuntament de Lleida, UIA, Ministerio de Asuntos Exteriores.

BRUNDTLAND, G. H. et al. (1987), Informe Brutndtland. Our common future. Oxford: Oxford University Press.

CAMPOS SÁNCHEZ, F. S. y ABARCA ÁLVAREZ, F. J. (2013), "Emplazamiento y localización en el origen y desarrollo de la forma urbana de las Ciudades Medias andaluzas de interior", Cuadernos Geográficos, núm. 52, págs. 288-317.

CANO GARCíA, G. (2008), "Clasificaciones urbanas en Andalucía: Las ciudades medias”, Revista de Estudios Andaluces, núm. 27, págs. 183-238.

CARAVACA, I., GONZÁlEZ, G., MÉNDEZ, R. y SILVA, R. (2002), Innovación Y Territorio, Análisis Comparado De Sistemas Productivos Locales En Andalucía. Sevilla: Consejería de Economía y Hacienda.

CHRISTALLER, W. (1993), Die zentralen Orte in Süddeutschland (Central Places in Southern Germany). Traducido por J. FISCHER. New Jersey: Prentice-Hall.

COMISIÓN EUROPEA (2000), Urban II. En línea: https://eur-lex.europa.eu/legal-content/ES/ TXT/? uri=LEGISSUM\%3Ag24209 (consulta: 27 de marzo de 2018).

CONFERENCIA DE LAS NACIONES UNIDAS (1992), Cumbre Mundial sobre Medio Ambiente y Desarrollo, Agenda 21. En línea: $h t t p: / / w w w . u n . o r g / s p a n i s h / e s a / s u s t d e v / a g e n d a 21$ (consulta: 10 de julio de 2017).

CONFERENCIA EUROPEA SOBRE CIUDADES SOSTENIBLES (1994), Carta de las Ciudades Europeas hacia la Sostenibilidad "Carta de Aalborg».

CONSEJO DE LA UNIÓN EUROPEA (2014), Desarrollo Urbano Sostenible Integrado. En línea: http://ec.europa.eu/ regional_policy/sources/docgener/informat/2014/urban_es.pdf (consulta: 27 de noviembre de 2017).

DE GREGORIO HURTADO, S. (2010), "El desarrollo de las iniciativas comunitarias URBAN y URBAN II en Ias periferias degradadas de las ciudades españolas. Una contribución a la práctica de la regeneración urbana en España", Ciudades, núm. 13, págs. 39-59. DOI: https://doi.org/10.24197/ciudades.13.2010.39-59.

DEL ESPINO HIDALGO, B. (2015), Sostenibilidad en centros históricos andaluces. Las ciudades medias del centro de Andalucía. Tesis Doctoral, Universidad de Sevilla. En línea: http://hdl.handle.net/11441/31236 (consulta: 11 de julio de 2017).

DEL ESPINO HIDALGO, B. (2016), "Patrimonio, planeamiento y participación: el papel de la ciudadanía en la protección patrimonial local”, Revista $P H$, núm. 90, págs. 222-224.

DEL ESPINO HIDALGO, B. (2017), "Las ciudades medias del centro de Andalucía. Aproximación a un fenómeno territorial y urbano", Revista de Estudios Regionales, núm. 108, págs. 165-191.

ELKINGTON, J. (1994), "Towards the Sustainable Corporation: Win-Win-Win Business Strategies for Sustainable Development”. California management review, vol. 36, núm. 2, págs. 90-100.

ENCUENTRO DE MINISTROS SOBRE DESARROLLO URBANO Y COHESIÓN TERRITORIAL (2007), Carta de Leipzig Sobre Ciudades Europeas Sostenibles. En línea: http://www.upv.es/contenidos/CAMUNISO/info/ U0506083.pdf (consulta: 10 de julio de 2017).

FERIA TORIBIO, J. M. (1984), "El sistema urbano andaluz: cuestiones metodológicas y problemas de información”, Revista de Estudios Andaluces, núm. 3, págs. 125-144.

GALINDO, J., "Indicadores urbanos (I): la dimensión cualitativa”, La Ciudad Viva, 13 de octubre de 2010. En línea: http://www.laciudadviva.org/blogs/?p=7204 (consulta: 10 de julio de 2014).

J. A. F., "Un nuevo plan estratégico trazará las líneas del futuro económico local", Diario Córdoba, 19 de diciembre de 2014. En línea: http://www.diariocordoba.com/noticias/lucena/nuevo-plan-estrategico-trazara-lineas-futuroeconomico-local_927852.html (consulta: 27 de noviembre de 2017). 
GAPP. Nueva Época - N. 20, noviembre 2018 - ISSN: 1989-8991 - DOI: 10.24965/gapp.v0i20.10481 - [Págs. 143-163] Número monográfico - Gobernanza y políticas de desarrollo urbano: teoría y práctica

Planeamiento estratégico local y evaluación del desarrollo urbano sostenible integrado en ciudades medias Blanca del Espino Hidalgo / Daniel Navas Carrillo

HIRSCHMAN, A. O. (1958), The strategy of economic development. New Haven: Yale University Press. DOI: https:// doi.org/10.1177/000271625932500118.

HUETE GARCÍA, M. A., MERINERO ROdRíGUEZ, R., MUÑOZ MORENO, R. (2014), "Políticas de regeneración urbana en España: Propuesta de análisis para su adecuación al Modelo Europeo de Desarrollo Urbano Integral”. Metodología de encuestas, núm. 16, págs. 45-66. DOI: https://doi.org/10.24965/gapp.v0i9.10085.

HUETE GARCíA, M. A., MERINERO RODRÍGUEZ, R., MUÑOZ MORENO, R. (2015), "Los sistemas locales de bienestar. Un análisis desde las políticas de regeneración urbana”, Revista de estudios políticos, núm. 169, págs. 201-233. DOI: $h$ ttps://doi.org/10.18042/cepc/rep.169.07.

HUETE GARCÍA, M. Á., MERINERO RODRÍGUEZ, R. y MUÑOZ MORENO, R. (2017), "El modelo de desarrollo sostenible integrado (DUSI). Análisis de la iniciativa urbana en España 2007-2013", en I Jornadas de Periferias Urbanas. Sevilla: Universidad de Sevilla. Escuela Técnica Superior de Arquitectura, págs. 319-332.

JUNTA DE ANDALUCÍA (2006), "Plan de Ordenación del Territorio de Andalucía". Boletín Oficial de la Junta de Andalucía, núm. 250, de 29 de diciembre de 2006, págs. 14-15.

JUNTA DE ANDALUCÍA (1994), Ley 1/1994 de Ordenación del Territorio de Andalucía. Plan de Ordenación del Territorio de Andalucía.

LLOP TORNÉ, J. M. y HOEFLICH DE DUQUE, S. (2010), Ciudades intermedias. Barcelona: Secretariado de la Red Mundial de Ciudades y Gobiernos Locales Unidos.

LÓPEZ ONTIVEROS, A. (1994), "La agrociudad andaluza: caracterización, estructura y problemática", Revista de Estudios Regionales, núm. 3, págs. 59-92.

LÖSCH, A. (1940), The Spatial Organization of the Economy. Londres: Encyclopædia Britannica.

MARTÍN MESA, A. y MERINERO RODRÍGUEZ, R. (2010), Planificación estratégica territorial: estudios metodológicos. Córdoba: Junta de Andalucía, Consejería de Gobernación y Justicia.

MERINERO RODRÍGUEZ, R. y LARA DE VICENTE, F. (2010), Las Ciudades Medias del interior de Andalucía. Caracterización y retos para el desarrollo turístico en un nuevo entorno. Córdoba: Aecit.

MINISTĖRE DU LOGEMENT ET DE L'HABITAT DURABLE (2017), Charte ÉcoQuartier. En línea: http://www.cohesionterritoires.gouv.fr/IMG/pdf/mise_en_page-25-01-charte_eq_2017.pdf (consulta: 10 de julio de 2017).

MINISTERIO DE HACIENDA Y ADMINISTRACIONES PÚBLICAS (2016), Resolución de 29 de septiembre de 2016, de la Secretaría de Estado de Presupuestos y Gastos, por la que se conceden ayudas de la primera convocatoria para la selección de estrategias de Desarrollo Urbano Sostenible e Integrado que serán cofinanciadas mediante el Programa Operativo FEDER de crecimiento sostenible 2014-2020, convocadas por Orden HAP/2427/2015, de 13 de noviembre.

NAVAS-CARRILLO, D. (2016), Innovación en la construcción de vivienda social en la primera periferia en las ciudades medias de Andalucía. El caso de Sanlúcar de Barrameda. Trabajo Fin de Máster, Universidad de Sevilla. En línea: http://hdl.handle.net/11441/53802 (consulta: 10 de julio de 2017).

NAVAS-CARRILLO, D., ROSA-JIMÉNEZ, C. y PÉREZ CANO, M. T. (2016), "Between Historic Sites and New Tourist Destinations: The Development of the First Periphery in Medium-Sized Andalusian Coastal Cities (1950-1980)", Athens Journal of Tourism, vol. 3, núm. 4, págs. 287-318.

ORDEN HAP/2427/2015, de 13 de noviembre, por la que se aprueban las bases y la primera convocatoria para la selección de estrategias de Desarrollo Urbano Sostenible e Integrado que serán cofinanciadas mediante el programa operativo FEDER de crecimiento sostenible 2014-2020.

ORGANIZACIÓN DE LAS NACIONES UNIDAS-ONU (2015), Objetivos de Desarrollo Sostenible. En línea: $h t t p: / / w w w$. un.org/sustainabledevelopment/es/objetivos-de-desarrollo-sostenible/ (consulta: 10 de julio de 2017).

PERROUX, F. (1955), "Note sur la notion de poles croissance”, Économic Appliquée, núm. 8, págs. 307-320.

PLOTNICOV, L. (1994), "El atractivo de las ciudades medias", Estudios Demográficos y Urbanos, vol. 9, núm. 2, págs. 283-301. DOI: https://doi.org/10.24201/edu.v9i2.908.

RFSC (2016), RFSC Newsletter. First issue. En línea: http://us13.campaign-archive2.com/?u=ff81151cb19b1864f66ec3 8d2\&id=94b76e0143 (consulta: 10 de julio de 2017).

RIU (2013), Iniciativas Urbanas. En línea: http://www.rediniciativasurbanas.es/que-es-la-riu/fondos-europeos-ydesarrollo-urbano/periodo-2007-2013/iniciativas-urbanas/ (consulta: 24 de julio de 2015).

RIU (2015), Orientaciones para la definición de estrategias de Desarrollo Urbano Sostenible Integrado en el periodo 2014-2020. En línea: http://www.rediniciativasurbanas.es/RIU/LANG_CASTELLANO/grupos_trabajo/grupo_ estrategias_dusi/ (consulta: 24 de julio de 2015).

SUBIRATS, J. (1994), Análisis de políticas públicas y eficacia de la Administración. Madrid: Ministerio para las Administraciones Públicas.

UNIÓN EUROPEA (2001), Cities of tomorrow: Challenges, visions, ways forward. En línea: http://ec.europa.eu/ regional_policy/sources/docgener/studies/pdf/citiesoftomorrow/citiesoftomorrow_final.pdf (consulta: 10 de julio de 2017).

VILAGRASA, J. (2000), Ciudades medias y ciudades intermedias: posicionamiento en la red urbana y procesos

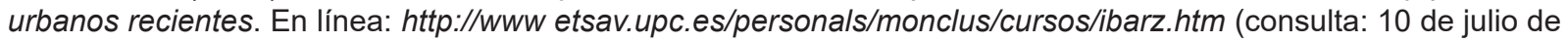
2017). 